\title{
Effect of bolts on flow and heat transfer in a rotor-stator disc cavity
}

\author{
Sulfickerali Noor Mohamed ${ }^{1}$ \\ Thermo-Fluid Systems UTC \\ Faculty of Engineering and Physical Sciences \\ University of Surrey \\ Guildford, Surrey, GU2 7XH, UK \\ Email: S.Noormohamed@surrey.ac.uk

\section{John W. Chew} \\ Thermo-Fluid Systems UTC \\ Faculty of Engineering and Physical Sciences \\ University of Surrey \\ Guildford, Surrey, GU2 7XH, UK \\ Email: J.Chew@surrey.ac.uk

\section{Nicholas J. Hills} \\ Thermo-Fluid Systems UTC \\ Faculty of Engineering and Physical Sciences \\ University of Surrey \\ Guildford, Surrey, GU2 7XH, UK \\ Email: N.Hills@surrey.ac.uk
}

\begin{abstract}
Previous studies have indicated some differences between steady CFD predictions of flow in a rotor-stator disc cavity with rotating bolts compared to measurements. Recently time-dependent CFD simulations have revealed the unsteadiness present in the flow and have given improved agreement with measurements. In this paper unsteady Reynolds averaged Navier-Stokes (URANS) $360^{\circ}$ model CFD calculations of a rotorstator cavity with rotor bolts were performed in order to better understand the flow and heat transfer

\footnotetext{
${ }^{1}$ Corresponding author.

Contributed by the International Gas Turbine Institute (IGTI) of ASME for publication in the JOURNAL OF ENGINEERING FOR GAS TURBINES AND POWER.
} 
ASME J Gas Turb Pwr

within a disc cavity previously studied experimentally by other workers. It is shown that the rotating bolts generate unsteadiness due to wake shedding which creates time-dependent flow patterns within the cavity. At low throughflow conditions, the unsteady flow significantly increases the average disc temperature. A systematic parametric study is presented giving insight into the influence of number of bolts, mass flow rate, cavity gap ratio and the bolts-to-shroud gap ratio on the time depended flow within the cavity.

Keywords: Gas turbine, internal air systems, unsteady flow, heat transfer, URANS, aero-engine, rotorstator disc cavity, bolts.

\section{Introduction}

In gas turbine internal air systems, disc cavities are cooled by the air bled from various stages of the compressor. Non-axisymmetric features such as boltheads present in the disc cavities will significantly heat the cooling air due to windage. In general windage for a rotor stator disc cavity with protrusions includes two loss components: viscous friction due to shear stresses within the boundary layer due to the relative velocity between the fluid and disc surface; and form drag due to separation of the air, as it passes over protrusions with resulting wake formation. Accurate predictions of flow and heat transfer in rotor-stator disc cavities facilitate improved thermo-mechanical design of the internal air system and surrounding components. This contributes to control of component temperatures and thermo-mechanical stress and displacement with associated benefits to thrust and efficiency.

Although steady CFD models have been shown to give reasonable results for many rotating disc flows including viscous friction in rotor-stator disc cavities, there is now 
considerable interest in unsteady flow effects. In some cases these can have undesirable consequences. For example, Dittmann et al. [1] found experimentally that with a low number of receiver holes, unstable flow occurred in their pre-swirl system, causing a severe decrease of discharge coefficient. They found that for a lower number of receiver holes with small spacing between the pre-swirl nozzles and holes, their direct transfer cooling air delivery system produced considerable unsteadiness. It is also known that rotating flows, such as those encountered in some internal air system designs can be subject to hysteresis [2], and the frequency response of such systems during engine transients is another area of interest [3]. As noted, for example, by Greenspan [4] rotating flows are susceptible to wave formation and this has been apparent in recent research on rotor-stator disc cavities with rim seal ingestion. For example, Cao et al. [5] and Jakoby et al. [6] have observed large scale flow structures in disc cavities with ingestion. These rotate at a lower speed than the disc. Identification of such structures has brought earlier modelling approaches into question, and this is a topical area of research. Full $360^{\circ}$ turbine stage unsteady CFD models and large-eddysimulation methods have recently been used in investigating such flows, as shown for example by O'Mahoney et al. [7] and Wang et al. [8].

Gunter and Uffrecht [9] have also recently highlighted the significance of unsteady effects in internal air systems. They carried out time resolved pressure measurements in a dual cavity test rig that models simplified internal cavities with receiver holes of an industrial gas turbine. Their test rig simulates restrictions imposed by internal blade cooling flow circuits. The angular resolved pressure measurements in the rotor-stator 
cavity showed peaks that correspond to 3 connecting holes and a higher frequency caused by 18 receiver holes. The authors also investigated influence of cavity gap ratio, rotational speed, and mass flow rate on the pressure fluctuations within the rotor-stator cavity. Higher rotational frequencies, narrow rotor-stator gap and high mass flow resulted in higher pressure fluctuations.

It has recently been shown that the flow associated with a rotating disc fitted with boltheads can display features comparable to rotating stall in a radial compressor [10]. Rotating stall is an unsteady flow phenomenon that involves rotating regions of reversed flow. According to Vagani et al. [11], in a centrifugal compressor, the flow distortions that make up rotating stall can appear with multiple lobes, or cells, distributed equidistantly around the impeller passage. The number of cells commonly varies between 1 and 5, with 3-cell stall being the most widely reported. In general the stall cells in compressors rotate around $50-60 \%$ of the rotor speed $[12,13]$. Such effects in bolted rotating disc cavities account for discrepancies between steady CFD modelling and experimental measurements noted in previous work [14]. It is clearly of interest to investigate the strength of these effects and the conditions under which they occur.

The present paper presents CFD investigations of the unsteady flow in a rotorstator disc cavity with boltheads on the rotor. It builds on the experimental research of Coren [15] and Miles [16] and earlier CFD studies by the present authors [10, 14]. It includes consideration of the effect of flow unsteadiness on heat transfer and the influence of bolt numbers, cavity geometry and flow rate on the flow structure. The geometry, CFD model, boundary conditions and the validation of disc temperature with 
experimental data are described in the next section. Details of the baseline flow and heat transfer are discussed in section 3.1. The parametric study varying number of bolts, cavity geometry and the throughflow Reynolds number about the baseline condition are discussed in section 3.2 to 3.5 with the main conclusions being summarized in section 4 .

\section{MODEL DESCRIPTION}

\subsection{TEST CASE CONSIDERED}

Figure 1a shows the general layout of the test rig used for the experiments at the University of Sussex $[15,16]$ and selected for this CFD study. A disc of $0.45 \mathrm{~m}$ diameter rotated up to $13000 \mathrm{rpm}$ powered by an electric motor with a gearbox. The disc was surrounded by cast steel housing. Compressed air was bled to both sides of the casing axially and was also expelled on both sides of the main casing. A torque meter measured the total torque due to windage from the rotation of the disc, with or without features on the rotor surface and a correction was made to subtract the contribution due to the driveline friction. In order to minimize axial bearing loading, equal flow and pressure conditions were imposed on both sides of the rotor during the experiments. A labyrinth rim seal installed inside the casing minimized leakage between the two sides of the disc. Rotor bolt tests were conducted using hexagonal bolts of $16 \mathrm{~mm}$ diameter. In addition to the torque measurements, infra red (IR) and laser Doppler anemometry (LDA) instrumentation were used to obtain disc surface temperature and tangential and radial velocity fields in the rotor-stator cavity. Figure $1 \mathrm{~b}$ shows the bolt orientation with respect to the disc rotation. More information for this test rig and experimental data is 
given by Coren [15] and Miles [16]. As reported by Miles [15], the uncertainty bars shown for the disc temperature in section 3 were calculated using the standard technique of root of the sum of the squares (RSS) of each component, of the uncertainty.

\subsection{CFD MODEL}

Steady and unsteady CFD analyses were performed for Coren's [15] experimental conditions with $16 \mathrm{~mm}$ diameter and $11 \mathrm{~mm}$ high hexagonal bolts fixed at $0.2 \mathrm{~m}$ disc radius $(r / b=0.89)$. CFD meshes were obtained using ICEM-CFD [17] following similar procedures to those developed and validated for steady and unsteady analysis in earlier studies $[10,14]$. The $360^{\circ}-18$ bolts model with boundary conditions is shown in figure 2a. Except where otherwise stated in section 3.1 the stator and rotor surfaces were assumed adiabatic. Distribution of grid points and a view of the mesh near the bolts from the same model are shown in figures $2 b$ and $2 c$. The bolts are numbered 1 to ' $n$ ' in the anti-clockwise direction, with bolt B1 located near the top dead centre.

All calculations were conducted in the rotating frame of reference. The steady CFD modelling followed the procedures described by Noor Mohamed et al. [14], and used the k- $\varepsilon$ turbulence model with standard wall functions in the Fluent CFD code [18]. Initial steady CFD simulations were carried out considering both sides of the disc. The moment coefficients from the balance side of the disc were found to be within $5 \%$ of those from the test side. The difference in wall temperature between test and balance 
side were found to be within $1 \mathrm{~K}$. To reduce the computational time, only the cavity on the right-hand side of the disc (test side) was considered for further calculations.

Details of the solver settings and boundary conditions used for the steady CFD are shown in Table 1. The unsteady calculations were started from converged steady state solutions. For unsteady simulations, the spatial discretization was 2 nd order and the solutions were advanced in time using a 2 nd order implicit method using the pressurebased coupled implicit solver. This converged faster than the segregated solver [19]. For unsteady calculations specified total pressure at the inlet was used as a more realistic boundary condition than specified mass flow. The total pressure specified was adjusted to achieve the desired average mass flow.

Details of mesh sensitivity studies performed for steady sector models and unsteady models were reported by Noor Mohamed et al. [10, 14]. Around 3 million hexahedral cells were used in the $360^{\circ}$ computational domain for the unsteady test cases considered. Standard wall functions with wall $y+$ values in the range of 20 to 200 were used for modelling the near wall flow physics. For the unsteady analysis, time steps corresponding to $0.10^{\circ}$ and $0.20^{\circ}$ rotor angular displacement at speed $\omega$ were used to investigate the time step sensitivity. The coarser time step resulted in almost identical swirl and temperature fluctuations at the monitor point to the shorter time step. Hence the coarser time step was used here.

The unsteady calculations were assumed to be converged when the flow values oscillated at a fixed frequency for at least 5 disc revolutions. This was monitored for several quantities including the moments on the stator and rotor walls, and swirl, total 
pressure and temperature probes inboard of the bolt $B 1$ at $\theta=10^{\circ}, r / b=0.82, x / s=0.4$ from the disc surface. The circumferential angle $\theta$ is defined from $-180^{\circ}$ to $+180^{\circ}$ in the anti-clockwise direction, where $\theta=0$ is located at the geometric plane of symmetry between bolt B1 and B18 for the 18 bolts case. For all other cases, $\theta=-180^{\circ}$ is located at the center of bolt B1. A $360^{\circ}-18$ bolts case with around 3.2 million cells in the computational domain took about 24 days to complete 40 disc rotations using 8 nodes with multiprocessors on a cluster computer.

\subsection{VALIDATION}

Validation of the unsteady CFD model against Coren's [15] experimental data for rotor torque, velocity measurements and disc temperature measurements is reported by Noor Mohamed et al. [10]. Both steady and unsteady CFD models give good agreement with torque measurements. Whereas steady CFD models underestimate the time-average swirl velocity in the cavity, unsteady CFD models show reasonable agreement with measurements. Although quantitative time resolved measurements were not taken during the experiments, Coren's [15] velocity measurements indicate that the flow near the protrusions is unsteady. The level of unsteadiness of the velocities given by the CFD is comparable to that in measurements.

A comparison of predicted and measured disc temperatures for the 18 and 9 bolts cases is reproduced from reference [10] in figure 3. Steady CFD and the URANS calculations predict similar air outlet temperatures. However steady CFD under-predicts the disc temperature inboard of the bolts. The difference in non-dimensional wall 
temperature between the steady CFD and measurement corresponds to an adiabatic wall temperature difference as high as 20K. URANS calculations capture the unsteady fluctuations and predict disc temperature profiles comparable with the experimental data for both cases. The difference in non-dimensional wall temperature between the URANS and measurement inboard of the bolts at $r / b=0.69$, corresponds to an adiabatic wall temperature difference of $\sim 3 \mathrm{~K}$ for the 18 bolts case and $\sim 1 \mathrm{~K}$ for the 9 bolts case. Coren's test rig includes a labyrinth rim seal installed inside the casing to minimize the leakage between the test and balance sides. To reduce the computational time, the labyrinth seal was omitted from the computational domain. The difference in adiabatic wall temperature between steady CFD/URANS calculation and the experimental data at higher radii $r / b=0.89$ and 0.94 could be due to the additional windage heating of the rotor from the labyrinth seal.

\subsection{RESULTS}

The results for a baseline condition with 18 bolts on the disc are presented in section 3.1 below. This case was considered in detail in reference [10] and is extended here to include heat transfer. Parametric studies are then presented in sections 3.2 to 3.5, with the emphasis on unsteady effects, but including comparison with measured torques where these are available. The studies varying the number of bolts, bolt to shroud gap and cavity gap are presented in sections 3.2 to 3.4. All the results in section

3.1 to 3.4 correspond to the simulated condition of $C_{w}=0.3 \times 10^{5}$ and $\lambda=0.09$. The 
results presented in section 3.5 looks into the influence of a higher throughflow Reynolds number of $C_{w}=10^{5}$ on the flow dynamics within the cavity.

\subsection{BASELINE FLOW AND HEAT TRANSFER}

The baseline test case corresponds to Coren's low throughflow condition with 18 bolts on the rotor. In this case the throughflow Reynolds number $C_{w}=3 \times 10^{4}$, the rotational Reynolds number $\operatorname{Re}_{\varnothing}=7.4 \times 10^{6}$, and the throughflow parameter $\lambda=0.09$. CFD results for this case were reported and analysed in detail in reference [10]. Full $360^{\circ}$ unsteady simulations revealed a clear 3 lobed structure in the inner part of the cavity, as shown in figure $4 a$. This structure rotates at $60 \%$ of disc speed in the stationary frame of reference, and is linked to the wake shedding from the bolts.

The unsteady flow has significant effects on the mean swirl velocity in the cavity and the adiabatic disc temperature, as is illustrated in figure 3 above. The investigation was extended here to show the effect of unsteadiness on heat transfer. A constant temperature (500K) boundary condition was applied on the rotor walls in both steady $20^{\circ}-1$ bolt and unsteady $360^{\circ}-18$ bolts models. This corresponds to a non-dimensional disc temperature of 9.6. Figure $4 \mathrm{~b}$ shows contours of instantaneous disc surface heat flux from unsteady CFD models after 40 disc rotations. As expected, unsteady CFD predicts a significantly asymmetric heat flux distribution on the disc surface due to the rotating 3-lobed flow cells within the cavity. Disc heat transfer is lower at locations where the bolt wake is aligned with the downstream bolt and higher at locations where the wake is shed towards the casing. 
Heat transfer results are further presented in the form of a local Nusselt number (Nu) on the rotor defined as follows:

$\mathrm{Nu}=\frac{\mathrm{hr}}{\mathrm{k}_{\mathrm{air}}}, \quad \mathrm{h}=\frac{\mathrm{q}_{\mathrm{w}}}{\mathrm{T}_{\mathrm{w}}-\mathrm{T}_{\mathrm{in}}}$

Here, $\mathrm{h}$ is the convective heat transfer coefficient, $\mathrm{k}_{\mathrm{air}}$ is the thermal conductivity of air, $\mathrm{q}_{\mathrm{w}}$ is the wall heat flux, $\mathrm{T}_{\mathrm{w}}$ is the wall temperature, and $\mathrm{T}_{\text {in }}$ is the inlet temperature. Figure $4 \mathrm{c}$ shows comparison of circumferentially averaged local Nusselt number from steady and unsteady CFD models. Due to the higher circumferentially averaged fluid total temperature inboard of the bolts, the unsteady CFD model predicts lower local heat flux from the disc. The maximum percentage difference in circumferentially averaged local Nu inboard of the bolts is $\sim 32 \%$ of the peak steady state Nusselt number.

\subsection{INFLUENCE OF NUMBER OF BOLTS}

To further understand the wake interaction effects, a systematic study was carried out using 3, 4, 9 and 18 bolts within the disc cavity. Figures $5 a$ and 5b show the instantaneous non-dimensional swirl and surface streamlines at a plane $\mathrm{x} / \mathrm{s}=0.25$ from the disc for 3, 4, 9 and 18 bolts models. All solutions were obtained using a full $360^{\circ}$ sector. Non-dimensional swirl is given by $\frac{\mathrm{v}_{\theta}}{\mathrm{r} \omega}$, where $\mathrm{V}_{\theta}$ is the tangential velocity in the absolute frame of reference. In these and other contour plots, the disc rotation is anticlockwise. URANS results from 3 and 4 bolts CFD models show circumferentially asymmetric flow patterns with 3 and 4 flow cells clearly forming in the inner part of the GTP-16-1330 
cavity. Flow into the cavity splits into 3 or 4 streams with spaces between these streams penetrated by vortices shed from the bolts. These flow cells rotate about $35 \%$ of rotor speed in the stationary frame of reference.

The contour plots of non-dimensional swirl for 9 and 18 bolts show wake-wake interactions resulting in 2 and 3 lobed flow cells within the cavity. For the 9 bolts case, reverse flow within the cavity strongly interacts with wakes of bolts $\mathrm{B} 3, \mathrm{~B} 1, \mathrm{~B} 5$, and $\mathrm{B} 7$. Wakes from other bolts are seen aligned more towards the casing. The streamlines show more asymmetry between the lobes than the 18 bolt case, since $9 / 2$ is noninteger. These cells rotate about $50 \%$ of rotor speed in the stationary frame of reference. For the 18 bolts case, it appears wakes from 4 to 5 bolts merge to form a single wake. The wake-wake and wake-casing interaction effects result in 3 flow cells within the cavity. These cells rotate about $60 \%$ of rotor speed in the stationary frame of reference.

Figure $5 c$ shows contours of non-dimensional disc wall temperature given by $\left(\frac{T_{w}-T_{i n}}{R_{b}^{2} \omega^{2} / 2 C_{p}}\right)$, where $T_{w}$ is the disc wall temperature and $T_{i n}$ is the inlet temperature. The 3 and 4 bolts unsteady solutions show three and four alternating hot and cold regions near the outer radii of the disc. The contour plot shows the hot region of the wake spanning about $50^{\circ}$ to $60^{\circ}$ of the disc circumferentially. For the 9 bolts case, weak wake interaction effects can be seen from the disc temperature plot. The 18 bolts case shows strong wake interaction effects. URANS calculation predicts significant disc heating inboard of the bolts, compared to the steady CFD calculation. The circumferentially 
averaged mean temperature inboard of the bolts from the URANS calculation is much higher than the circumferential averaged value from the steady CFD solution.

Three dimensional details of the large scale wake vortex structures from protrusions can be identified using the Q-criterion. The Q-criterion identifies vortices as flow regions with positive second invariant of the velocity gradient tensor, which represents the strength of rotation over mean strain rate. Iso-surfaces of the Q-criterion for the 3, 9 and 18 bolts cases are shown in figure 6 with similar values for all three cases. Comparing with a schematic of flow over a truncated cylinder by Pattenden et al. [20], the 3 bolts case shows the separated horseshoe vortex from the base of the protrusion, tip vortex from the top surface of the bolt and the strong bolt wake vortices shedding towards the casing. For the 9 bolts case wakes from the upstream bolts can be seen merging and strengthening the downstream bolt wake. Similarly for the 18 bolts case, wakes from 4 to 5 bolts are seen merging and strengthening the downstream wake to help form the 3 lobed flow cells within the disc cavity.

More details of the unsteady flow dynamics are illustrated with the help of contours of instantaneous flow angle in figure 7. Here flow angle is defined as the angle the resultant of the tangential and radial velocity components make with the radial line, as shown in figure 7 a. The flow angle $\alpha$ will be $90^{\circ}$ for flow with a zero or negligible radial velocity component. The yellow contours inboard of the bolts in the figure 7 show higher flow angles, which occur when the bolt wakes divert the flow towards the inner radius of the disc cavity. For the 9 bolts case, from $t / T=0.01$ to 0.29 , the region of high flow angle inboard of the bolt 1 (B1) moves to a location inbetween bolt 8 (B8) and bolt 
9 (B9) in the clockwise direction. Similarly for the 18 bolts case, from $t / T=0.01$ to 0.29 , the region of high flow angle moves from bolt 3 (B3) to bolt 1 (B1) in the clockwise direction. The flow cells for the 9 bolts and 18 bolts case rotate at around $50 \%$ and $40 \%$ of the disc speed respectively in the rotating frame.

Rotating stall in compressors is associated with flow separation in a blade passage (or group of blade passages) deflecting the flow so that upstream blades are likely to stall and downstream blades are likely to un-stall. Figure 7e suggests a similar mechanism for the present flow, with the inflow regions deflecting the outflow which in turn alters the angle of impingement of the flow on the bolts and the interaction with the shroud. More details of the flow angle variation and the circumferential and radial drag variation of individual bolts at various times for the 18 bolts case are given by Noor Mohamed et al. [10].

The radial variation of the relative velocity at a line $x / s=0.25$ from the disc surface on the geometric plane of symmetry between bolt B1 and B2 was analysed for the 18 bolts case. The average relative velocity on the geometric plane of symmetry between bolt B1 and B2 varies between $32 \mathrm{~m} / \mathrm{s}\left(\frac{V_{\text {rel-avg }}}{\mathrm{b} \omega}=0.15\right)$ to around $75 \mathrm{~m} / \mathrm{s}\left(\frac{V_{\text {rel-avg }}}{\mathrm{b} \omega}=0.36\right)$ over 0.42 of a disc rotation. The Reynolds number calculated using the average relative velocity and bolt diameter falls in the range between $8.29 \mathrm{E}+4$ to $1.96 \mathrm{E}+5$. Comparison with the flow past a circular cylinder, suggests that the flow regime is sub-critical, so that regular vortex shedding characterised by turbulent vortex street might be expected [21]. 
A comparison of non-dimensional radial velocity inboard of the bolts from steady CFD with instantaneous values from the URANS calculation for the 3 and 18 bolts cases is shown in figure 8 . The steady state CFD shows uniform circumferential distribution of the radial throughflow amongst the bolts for both cases. For the 3 bolts case, the time resolved computation shows positive and negative radial throughflow inbetween the bolts. The 18 bolts case shows variation of radial throughflow for a group of 6 bolts due to the merging of wakes.

The interaction of the wake vortices and flow cells with the casing is illustrated by the instantaneous static pressure variation on the stator surface. Figure 9 shows the static pressures on the casing surface at $x / s=0.25$ from the disc surface nondimensionalized using the dynamic head at disc speed. Lower static pressures are at locations where flow tends to move away from casing. The instantaneous values for the 3 bolts case show a drop in static pressure every $60^{\circ}$. This profile varies with time, as do the details of the 3 lobed flow structure. The 4 bolts case forms 4 stable circumferential pressure peaks corresponding to the rotating flow cells. The 9 and 18 bolts show 2 and 3 circumferential pressure peaks due to the superposition of wakes and the resulting flow cells within the cavity. At around $120^{\circ}$ circumferential location, the 9 bolts case shows more static pressure variation compared to the 18 bolts case. This may be due to the strongest flow cell pushing the flow radially towards the casing. The maximum and minimum non-dimensional circumferential casing pressures for the 9 bolts case are 0.09 and -0.02 . For the 18 bolts case the maximum and minimum values are 0.06 and -0.036 . 
The unsteady pressure was recorded from numerical probes inboard of the bolts inside the rotor-stator cavity in the rotating frame of reference. Spectral analysis of the pressure signal was carried out using Discrete Fourier Transforms (DFT) of the recorded static pressure signals. Figure 10 shows results of the DFT for the pressure fluctuations inboard of bolt $B 1$ at the point $r / b=0.82, x / s=0.4$ from the disc surface for different cases. This shows, two pressure peaks for 3 and 4 bolts cases. The peak amplitudes and frequencies at which they occur for the various cases are given in table 2 . The $f / f_{d}$ values of 1.84 and 2.4 from the 3 and 4 bolts case are the frequencies corresponding to the rotating flow cells. These rotate at about $65 \%$ of the disc speed in the rotating frame. The 9 bolts case shows 4 pressure peaks with two of the peaks overlapping with the peak frequencies from the 3 bolts case. For the 9 bolts case, 4 lobed flow cells were observed during the initial few rotations which subsequently merged to form the 2 lobed flow cells. Modification in strength of the 2 lobes and tendency to form a 3 lobed structure were also observed over several disc rotations for the 9 bolts case. The 4 pressure peaks at different frequencies observed in the spectrum are associated with the instability of the rotating flow cells. The 2 -lobed flow cells rotate about $50 \%$ of the disc speed in the rotating frame. The 18 bolts case shows a clear dominant pressure peak of non-dimensional value 0.043 at $f / f_{d} \sim 1.4$. This corresponds to the 3 -lobed flow cell and rotates about $40 \%$ of the disc speed in rotating frame.

Comparison of the total moment coefficient $\left(C_{m}\right)$ for both sides of the disc from the steady and unsteady CFD with Coren's [15] experimental data is given in Table 3. For all 
ASME J Gas Turb Pwr

cases, $C_{m}$ calculated from the steady and unsteady CFD is within $+/-6 \%$ of the experimental value. This variation is within the experimental uncertainty [14].

\subsection{INFLUENCE OF BOLTS TO SHROUD GAP RATIO}

A study was carried out to understand the effect of changing the proximity of bolts to the shroud. Here the bolts-to-shroud gap ratio $E$, is defined as $e / b$, where e is the radial distance between the bolts outboard flat surface and the shroud and $b$ is the disc outer radius. The bolts-to-shroud gap ratio corresponding to the baseline case is 0.08 . The gap ratio was changed by moving the shroud outboard and inboard without altering the radial location of the bolts. The notation ' $2 \mathrm{E}$ ' and ' $0.5 \mathrm{E}$ ' corresponds to bolt to shroud gap ratios of 0.16 and 0.04 respectively. In all these cases rotor speed $\omega$ and the imposed flow rate $\dot{\mathrm{m}}$ were kept at the values used in the baseline model.

Comparisons of the instantaneous non-dimensional swirl, surface streamlines and non-dimensional disc temperature for the higher and lower bolt to shroud gap ratio cases are given in figure 11 . These may be compared with results for the baseline 18 bolts case in figure 5 . As the shroud is moved outward, the occurrence of merged wakes is more obvious and appears to be strengthened. This results in change of the flow structure inside the disc cavity from 3-lobed to 2-lobed flow cells. Similarly as the shroud is moved inboard, wakes from fewer bolts combine. The strength of the 3 lobed flow cells is weaker than for the baseline case.

Figures $12 \mathrm{a}$ and $\mathrm{b}$ show the instantaneous non-dimensional swirl in board of the bolt $\mathrm{B} 1$ for 6 disc rotations $(\mathrm{r} / \mathrm{b}=0.82, \mathrm{x} / \mathrm{s}=0.4)$ and the circumferential variation of the GTP-16-1330 
non-dimensional radial velocity at the same location. The higher bolts-to-shroud gap, with the 2 lobed flow structure shows noticeably higher levels of fluctuation. The lower bolts-to-shroud gap ratio with a weaker 3 lobed flow structure results in lower time averaged swirl inboard of the bolts and lower radial velocity variation amongst the bolts.

Figure 13 shows the instantaneous static pressure on the casing surface at $\mathrm{x} / \mathrm{s}=$ 0.25 for various bolts-to-shroud gap ratios. As expected, the higher shroud gap ratio case shows two pressure peaks circumferentially due to wake-wake interaction and the resulting formation of 2-lobed flow cells within the cavity. The lower shroud gap ratio shows multiple pressure peaks circumferentially due to the casing restricting the wakewake interaction among the bolts.

Figure 14 shows results of the DFT for the pressure fluctuations in the cavity inboard of bolt $B 1$ at $r / b=0.82, x / s=0.4$. With the increase in bolts-to-shroud gap, the normalized 1 st harmonic frequency shifts to $f / f_{d}=0.87$ and shows $\sim 35 \%$ increase in peak pressure. The higher shroud gap case also shows peak pressure fluctuations at 3 higher frequencies. The lower shroud gap ratio results in several low pressure peaks of different frequencies. This may be due to the instability of rotating structures. The highest peak pressure is of non-dimensional value 0.031 at a non-dimensional frequency of about 2.86. The total moment coefficient from the bolts and disc for both sides obtained from steady and unsteady calculation for the ' $0.5 \mathrm{E}^{\prime}$ case are very similar around 0.0165 . However, the time averaged $C_{m}$ for the ' $2 E^{\prime}$ case 0.0197 is $\sim 7 \%$ higher than the $C_{m}$ calculated from steady CFD. 


\subsection{INFLUENCE OF CAVITY GAP RATIO}

To understand the influence of cavity gap ratio $\mathrm{G}(=\mathrm{s} / \mathrm{b})$ analysis was repeated for $\mathrm{G}=0.2$, twice the baseline gap ratio. Figure 15 shows instantaneous swirl fluctuations inboard of the bolt B1 for the baseline case and for similar conditions with $G=0.2$. As the cavity gap ratio is doubled the unsteadiness within the cavity reduces significantly. The steady CFD predicts higher non-dimensional swirl at $x / s=0.4$ near the bolt due to lower stator drag. However, the difference between steady state swirl and time averaged values from URANS calculations at higher gap ratio is significantly lower than for the baseline case. The circumferential distribution of the static pressure on the casing surface was analyzed and as expected, the higher cavity gap ratio case shows lower circumferential variation of casing pressure. DFT of pressure fluctuations inboard of the bolt $B 1$ shows around $32 \%$ reduction in peak pressure at $f / f_{d}=1.4$. The time averaged $C_{m}$ for the $G=0.2$ case is 0.0184 which is $\sim 3.3 \%$ lower than the $C_{m}$ from steady CFD, and compares to 0.0178 for the baseline case.

Figure 16 shows the profile of circumferentially averaged non-dimensional disc temperature from steady and unsteady CFD models for the two cases. It can be seen that the circumferential average disc temperature profile inboard of the bolts from steady CFD for $\mathrm{G}=0.2$ is inbetween the disc temperature profile predicted for $\mathrm{G}=0.1$ and those from steady flow models. As the gap ratio increases, the influence of flow mixing due to wake shedding on disc temperature profile becomes weaker. Consequently, steady and unsteady CFD solutions are closer. 


\subsection{INFLUENCE OF MASS FLOW RATE}

To understand the influence of mass flow rate, the baseline configuration analysis was repeated for a higher throughflow Reynolds number of $C_{w}=10^{5}$. Figure 17 shows the contours of instantaneous non-dimensional swirl, surface streamlines at $x / s=0.25$ from disc surface and disc surface temperature. The contours of instantaneous swirl show multiple rotating structures within the cavity. The rotating cells within the cavity seem to be unstable and not totally coherent. It appears that the higher throughflow results in an increase of the number of lobes in the flow structure and greater flow instability.

Figure 18 shows the instantaneous circumferential variation of radial velocity inboard of bolts B1. Wakes from no more than 3 bolts are seen to merge, for the higher flow case. The static pressure distribution on the casing surface was also analyzed and it shows considerably higher pressure fluctuations compared to the low throughflow case with variation in the range of $0.08<\mathrm{p} /\left(0.5 \rho \omega^{2} \mathrm{~b}^{2}\right)<0.27$ compared to $-0.036<$ $\mathrm{p} /\left(0.5 \rho \omega^{2} \mathrm{~b}^{2}\right)<0.065$ for the baseline case. For the high throughflow case, the total moment coefficients from the steady (0.0274) and unsteady (0.0262) CFD are around $18 \%$ and $13 \%$ higher than the moment coefficient from the measured disc torque.

Figure 19 compares frequency spectra of pressure fluctuations inboard of the bolts for the baseline and high throughflow cases. The high throughflow shows significant pressure fluctuations with normalized frequency of 2.2 for the 1 st harmonic. The nondimensional peak pressure at this point is 0.062 , around $45 \%$ higher than the corresponding peak pressure for the baseline case. The high throughflow case also 
shows 3 other non-dimensional pressure peaks $\sim 0.03$ to $\sim 0.033$ corresponding to normalized frequencies of $3.32,3.82$ and 4.4 . The multiple pressure peaks are associated with the instability of rotating flow cells within the cavity.

\section{CONCLUSIONS}

Unsteady CFD modelling of a rotor-stator disc cavity with boltheads on the rotor using $360^{\circ}$ models has been performed and has given new insight into the flow in such systems. Time-resolved large sector CFD calculations reveal complex wake interactions and unsteadiness within the disc cavity and confirm experimental measurements of unsteadiness, showing reasonable agreement with the available mean flow and temperature measurements. A parametric study was presented in this paper to understand the influence of number of bolts, cavity geometry and radial throughflow rate on the flow dynamics within the cavity. The conclusions can be summarized as follows:

1. The URANS calculations show wake shedding and unsteady flow within the cavity for all cases investigated. Flow structures with 2 to 4 circumferential lobes rotating at $35 \%$ to $60 \%$ rotor speed in the stationary frame of reference were observed. These structures significantly affect the mean flow in the cavity, the adiabatic disc temperature and the mean disc heat transfer coefficient.

2. The 3 and 4 bolts cases show 3 and 4 circumferential rotating lobes due to wake shedding into the cavity. Increasing the number of bolts results in wake-wake interactions and merging of the wakes. The 9 bolts case shows an asymmetric 2 lobed 
structure. The 18 bolts case forms a symmetric 3 lobed rotating structure. The 18 bolts case shows a clear dominant pressure peak of non-dimensional value 0.043 at a frequency, $f / f_{d}$ of around 1.4.

3. For the 18 bolts case, a higher bolt-to-shroud gap results in higher unsteadiness and mixing of the hot fluid into the cavity. As the shroud is moved outwards, wakes from more bolts merge to form a 2 lobed rotating structure. Reducing the bolts-toshroud gap weakens the wake interactions and the strength of rotating structure within the cavity. Thus reducing the bolts-to-shroud gap could be effective in reducing the unsteady effects in the disc cavity.

4. As the width of the cavity is doubled, the unsteadiness within the cavity reduces. The disc temperature profile inboard of the bolts from steady CFD is then closer to the circumferentially averaged profile from URANS calculations. This could be due to less restricted recirculation within the cavity due to higher rotor-stator gap. The higher gap ratio case shows $\sim 32 \%$ reduction in pressure fluctuations at a normalized frequency $f / f_{d}$ of $\sim 1.4$.

5. A higher throughflow results in higher unsteadiness and more unstable rotating structures within the cavity. The pressure peak corresponding to the 1st harmonic frequency is about $45 \%$ higher than the corresponding pressure peak for the low throughflow case.

It is clear that the unsteady flows shown here significantly alter flow and heat transfer within the cavity. Another interesting and important possibility is that in an engine configuration rotating flow modes associated with boltheads might couple with 
other sources of unsteadiness. These could include unsteadiness due to other nonaxisymmetric geometrical features and natural flow unsteadiness such as that in turbine rim seals. In a recent paper Liu et al. [22] have investigated effects of rotor protrusions on turbine rim seal ingestion, with experiments indicating reduced ingestion levels on the stator disc when protrusions are present on the rotor.

\section{ACKNOWLEDGMENTS}

The authors wish to express their appreciation to Dr. Daniel Coren for answering many queries related to the Sussex bolt windage test. The authors also express gratitude to Rolls-Royce plc and the Clean Sky Joint Technology Initiative for providing financial support for this work. 


\section{NOMENCLATURE}

b Disc outer radius, $\mathrm{m}$

$\mathrm{C}_{\mathrm{p}} \quad$ Specific heat at constant pressure, J/kg K

$C_{m} \quad$ Moment coefficient $\left(\frac{M}{1 / 2 \rho \omega^{2} b^{5}}\right.$ for both sides of the disc)

$\mathrm{C}_{\mathrm{w}} \quad$ Throughflow Reynolds number $\left(=\frac{\dot{m}}{\mu b}\right)$

D Diameter of bolts (measured across flats), $m$

e Bolt to shroud radial distance, $m$

E Bolt to shroud gap ratio ( $=\mathrm{e} / \mathrm{b})$

f Frequency of rotation, $\mathrm{Hz}$

$f_{d} \quad$ Disc rotational frequency, $\mathrm{Hz}$

G Cavity gap ratio ( = s/b)

h convective heat transfer coefficient, $W /\left(m^{2} \mathrm{~K}\right)$

$k_{\text {air }}$ Thermal conductivity of air, $\mathrm{W} /(\mathrm{m} \mathrm{K})$

M Torque on both sides of the disc, $\mathrm{Nm}$

$\dot{\mathrm{m}}$ Mass flow rate, $\mathrm{kg} / \mathrm{s}$

$\mathrm{Nu} \quad$ Nusselt number

n Number of bolts

$\mathrm{P}_{\mathrm{s}} \quad$ Static pressure, $\mathrm{Pa}$

$\mathrm{p} \quad$ Pressure, $\mathrm{Pa}$

$q_{w} \quad$ Wall heat flux, $\mathrm{W} / \mathrm{m}^{2}$

$R_{b} \quad$ Radial location of the bolts, $m$

$\operatorname{Re}_{\emptyset} \quad$ Rotational Reynolds number $\left(=\frac{\rho \omega b^{2}}{\mu}\right)$

$r \quad$ Local radius, radial direction, $\mathrm{m}$

$\mathrm{s} \quad$ Disc-to-stator axial spacing, $\mathrm{m}$

t Flow time (from start of current period), $\mathrm{s}$ 
ASME J Gas Turb Pwr

$\mathrm{T} \quad$ Time for one disc revolution, $\mathrm{s}$

$\mathrm{T}_{\text {in }} \quad$ Inlet total temperature, $\mathrm{K}$

$\mathrm{T}_{\mathrm{w}} \quad$ Wall static temperature, $\mathrm{K}$

$u_{f} \quad$ Friction velocity $\left(=\sqrt{\tau_{w} / \rho}\right), \mathrm{m} / \mathrm{s}$

$\mathrm{V}_{\theta} \quad$ Tangential velocity, $\mathrm{m}$

$\frac{V_{\theta}}{r \omega} \quad$ Swirl, non-dimensional swirl

$\mathrm{V}_{\mathrm{r}} \quad$ Radial velocity, $\mathrm{m}$

$\mathrm{V}_{\text {rel-avg }}$ Average relative free stream velocity, $\mathrm{m} / \mathrm{s}$

$\mathrm{V}_{\theta, \mathrm{r}} \quad$ Resultant of tangential and radial velocity, $\mathrm{m} / \mathrm{s}$

$y^{\prime} \quad$ Normal distance from the wall, $m$

$\mathrm{x}, \mathrm{y}, \mathrm{z}$ Cartesian co-ordinates

$\mathrm{y}+\quad$ non-dimensional wall distance $\left(=y^{\prime} u_{f} / \mu\right)$

\section{Greek symbols}

$\begin{array}{cl}\Delta \mathrm{T}_{\mathrm{w} \text {-non }} & \text { Non-dimensional temperature difference }\left(\frac{\mathrm{T}_{\mathrm{w}}-\mathrm{T}_{\mathrm{in}}}{\mathrm{R}_{\mathrm{b}}^{2} \omega^{2} / 2 \mathrm{C}_{\mathrm{p}}}\right) \\ \varepsilon & \text { Turbulence dissipation rate, } \mathrm{m}^{2} / \mathrm{s}^{3} \\ \mathrm{k} & \text { Turbulent kinetic energy, } \mathrm{m}^{2} / \mathrm{s}^{2} \\ \lambda & \text { Throughflow parameter }=\frac{C_{w}}{R e_{\varnothing}{ }^{0.8}} \\ \mu & \text { Dynamic viscosity, } \mathrm{kg} / \mathrm{m} . \mathrm{s} \\ \omega & \text { Disc speed, rad } / \mathrm{s} \\ \rho & \quad \text { Fluid density, } \mathrm{kg} / \mathrm{m}^{3} \\ \alpha & \text { Flow angle, degree } \\ \Theta & \text { Circumferential angle, degree } \\ \tau_{w} & \text { Wall shear stress, Pa }\end{array}$




\section{REFERENCES}

[1] Dittmann M., Geis T., Schramm V., Kim S., and Wittig S., 2002 “Discharge coefficients of a pre-swirl system in secondary air systems", ASME J Turbomach., 124:119-124

[2] May D, Chew JW., 2010 "Response of a Disk Cavity Flow to Gas Turbine Engine Transients", ASME Paper No. GT2010-22824

[3] May D, Chew JW, Scanlon TJ., 2013 “Prediction of Deswirled Radial Inflow in Rotating Cavities With Hysteresis", ASME J Turbomach., 135 (4)

[4] Greenspan, H.P., "The theory of rotating fluids", Cambridge, 1968.

[5] Cao, C., Chew, J.W., Millington, P.R. and Hogg, S.I., 2004 "Interaction of Rim Seal and Annulus Flow in an Axial Flow Turbine", " ASME J. Eng. Gas Turb. Power, 126:786793.

[6] Jakoby, R., Zierer, T., Lindblad, K., Larssson, J., deVito, L., Bohn, D. E., Funcke, J., and Decker, A., 2004, "Numerical Simulation of the Unsteady Flow Field in an Axial Gas Turbine Rim Seal Configuration," ASME Paper No. GT2004-53829.

[7] O'Mahoney, T.S.D., Hills, N. J., Chew, J. W., Scanlon, T., (2011) “Large-Eddy simulation of rim seal ingestion". Proceedings of the Institution of Mechanical Engineers, Part C: Journal of Mechanical Engineering Sciences, 225 (C12), pp. 28812891. 
[8] Wang, C., Mathiyalagan, S., Johnson, B. V., Glahn, J., Cloud, D. F., "Rim Seal Ingestion in a Turbine Stage From 360 Degree Time-Dependent Numerical Simulations", ASME J Turbomach., 2013;136(3)

[9] Günther, A., Uffrecht, W., Caspary, V., "Time-Resolved Pressure Measurements at a Dual-Cavity Test Rig for Research on the Internal Air System of an Industrial Gas Turbine", Proceedings of ASME Turbo Expo Düsseldorf 2014, GT2014-26231.

[10] Noor Mohamed, S., Chew, J.W. and Hills, N.J., 2016 "Flow and windage due to bolts on a rotating disc", Proceedings of the Institution of Mechanical Engineers, Part C: Journal of Mechanical Engineering Sciences.

[11] Vagani, M., Engeda, A., and Cave, M, J., 2013 "Prediction of impeller rotating stall onset using numerical simulations of a centrifugal compressor. Part 1: Detection of rotating stall using fixed-flow transient simulations", Proc IMechE Part A: J Power and Energy.

[12] Arnulfi, G. L., Micheli, D., and Pinamonti, P., 1996 “Experimental Investigation on Rotating Stall in a Centrifugal Blower With Two and Four Stages and Vaneless Diffusers", ASME Paper No. 96-GT-171.

[13] Saxer-Felici, H. M., Saxer, A., Inderbitzin, A., and Gyarmathy, G., 1999 "Prediction and Measurement of Rotating Stall Cells in an Axial Compressor", ASME J Turbomach., Vol. 121, pp. 365-375

[14] Noor Mohamed, S., Chew, J.W. and Hills, N.J., 2015 "Simplified protrusion drag and heat transfer modelling of bolts on a rotating disc", ASME Paper No. GT2015-43501. 
[15] Coren, D., 2007 "Windage due to Protrusions in Rotor-Stator Systems", ThermoFluid Mechanics Research Centre, University of Sussex, D. Phil Thesis.

[16] Miles, A., 2011 "An Experimental Study of Windage due to Rotating and Static Bolts in an Enclosed Rotor-Stator System", Thermo-Fluid Mechanics Research Centre, University of Sussex, D. Phil Thesis.

[17] ICEMCFD manual, ICEMCFD 14 User manual. Ansys Inc. 2011

[18] ANSYS FLUENT 14.0 User's Guide, October 2012, Ansys Inc.

[19] Young, C., 2013 "An Evaluation of the Pressure-Based Coupled Solver in ANSYS FLUENT-v12", ANSYS Regional Conference Proceedings.

[20] Pattenden, R. J., Turnock, S. R. \& Zhang, X. 2005 “Measurements of the flow over a low-aspect ratio cylinder mounted on a ground plane", Exp. Fluids 39, 10-21.

[21] Lienhard, J.H., 1966 "Synopsis of lift, drag and vortex frequency data for rigid circular cylinders", Washington State University, College of Engineering, Research Division Bulletin 300.

[22] Liu, D., Tao, Z., Luo, X., Kang, W., Wu, H., and Yu, X., 2016, "Investigation on the Impact of Protrusion Parameter on the Efficiency of Converting Additional Windage Loss for Ingress Alleviation in Rotor-Stator System," ASME J. Eng. Gas Turb. Power, 138(7) p. 072501. 


\section{Tables with their Captions}

Table 1 . Solver settings and boundary conditions used for the steady flow analysis

\begin{tabular}{|c|c|}
\hline Solver & $\begin{array}{l}\text { Segregated, implicit, steady state solver with absolute } \\
\text { velocity formulation. }\end{array}$ \\
\hline $\begin{array}{l}\text { Boundary } \\
\text { conditions }\end{array}$ & $\begin{array}{l}\text { Disc: no-slip, adiabatic, rotating at speed } \omega \text { as defined by } \\
\text { experimental data being modeled. } \\
\text { Casing: no-slip, adiabatic, stationary. } \\
\text { Inlet(s): mass flow and total temperature set from } \\
\text { experimental data. Zero swirl, } 5 \% \text { turbulence intensity and } \\
\text { length scale equal to } 0.07 x \text { hydraulic diameter. } \\
\text { Outlet(s): constant pressure outlet, static pressure set to } 0 \mathrm{~Pa} \\
\text { relative to the operating condition }\end{array}$ \\
\hline Fluid & Air modeled as an ideal gas. \\
\hline Solver Control & $\begin{array}{l}\text { 2nd order discretization set on all variables including energy } \\
\text { equation, PRESTO for the pressure solution. }\end{array}$ \\
\hline
\end{tabular}


Table 2.Normalized frequency and peak pressures for different bolt numbers

\begin{tabular}{ccc}
\hline $\begin{array}{c}\text { Number of } \\
\text { bolts }\end{array}$ & $\mathrm{f} / \mathrm{f}_{\mathrm{d}}$ & Pressure/(0.5 $\left.\rho \omega^{2} \mathrm{~b}^{2}\right)$ \\
\hline 3 & 1.84 & 0.012 \\
& 3.76 & 0.015 \\
\hline \multirow{2}{*}{4} & 2.4 & 0.029 \\
& 4.81 & 0.013 \\
\hline \multirow{2}{*}{9} & 0.95 & 0.029 \\
& 1.85 & 0.014 \\
& 2.75 & 0.015 \\
& 3.7 & 0.024 \\
\hline \multirow{2}{*}{18} & 1.4 & 0.043 \\
& 2.9 & 0.006 \\
\hline \hline
\end{tabular}

Table 3. Comparison of $\mathrm{C}_{m}$ from Steady CFD, URANS calculations and Coren's [15] experimental data

\begin{tabular}{cccc}
\hline $\begin{array}{c}\text { Number } \\
\text { of bolts }\end{array}$ & $\begin{array}{c}\mathrm{C}_{\mathrm{m}}{ }^{-} \\
\text {Steady } \\
\text { CFD }\end{array}$ & $\begin{array}{c}\mathrm{C}_{\mathrm{m}}- \\
\text { URANS } \\
\text { Time } \\
\text { Avg. }\end{array}$ & $\begin{array}{c}\mathrm{C}_{\mathrm{m}}- \\
\text { Experiment - } \\
\text { Coren [15] }\end{array}$ \\
\hline 3 & 0.0112 & 0.0113 & 0.0118 \\
\hline 4 & 0.0123 & 0.0122 & $\mathrm{NA}$ \\
\hline 9 & 0.0153 & 0.0149 & 0.0145 \\
\hline 18 & 0.0180 & 0.0178 & 0.0174 \\
\hline \hline
\end{tabular}


Figures with their Captions

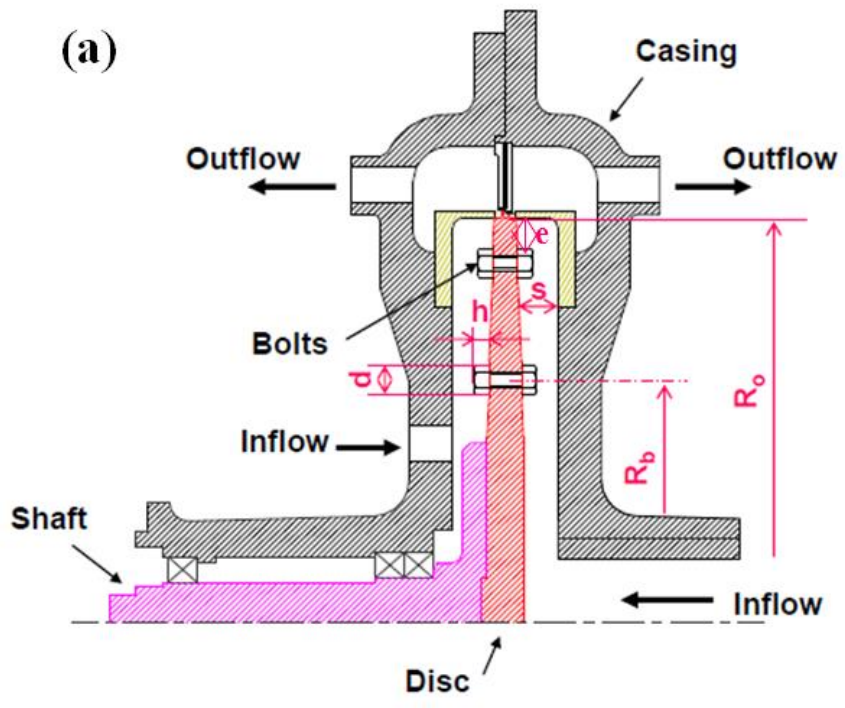

(b)

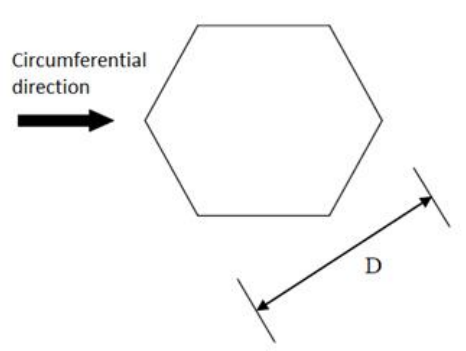

Figure 1. (a) Bolt Windage Rig-University of Sussex (Coren [15]) (b) bolt orientation with respect to direction of rotation (Miles [16])

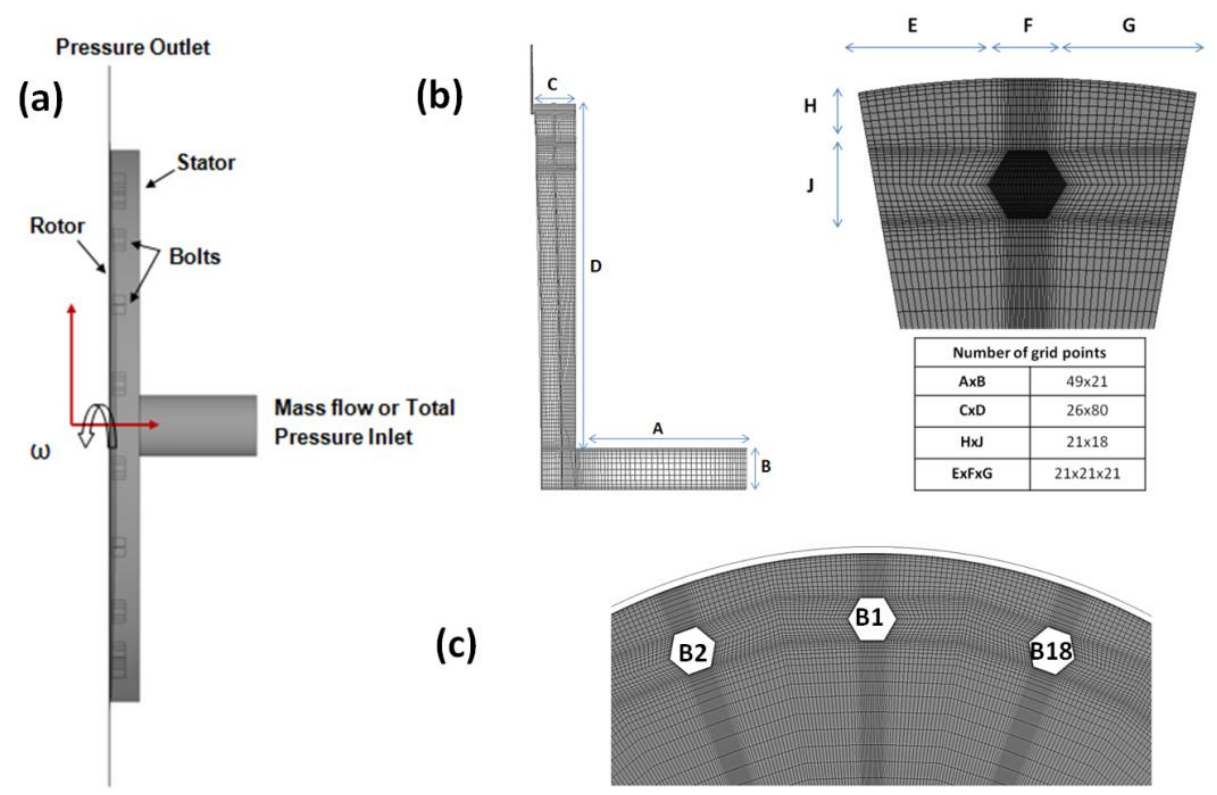

Figure 2. (a) Boundary conditions and (b) Distribution of grid points and (c) view of mesh near the bolts for $360^{\circ}-18$ bolts model 
ASME J Gas Turb Pwr

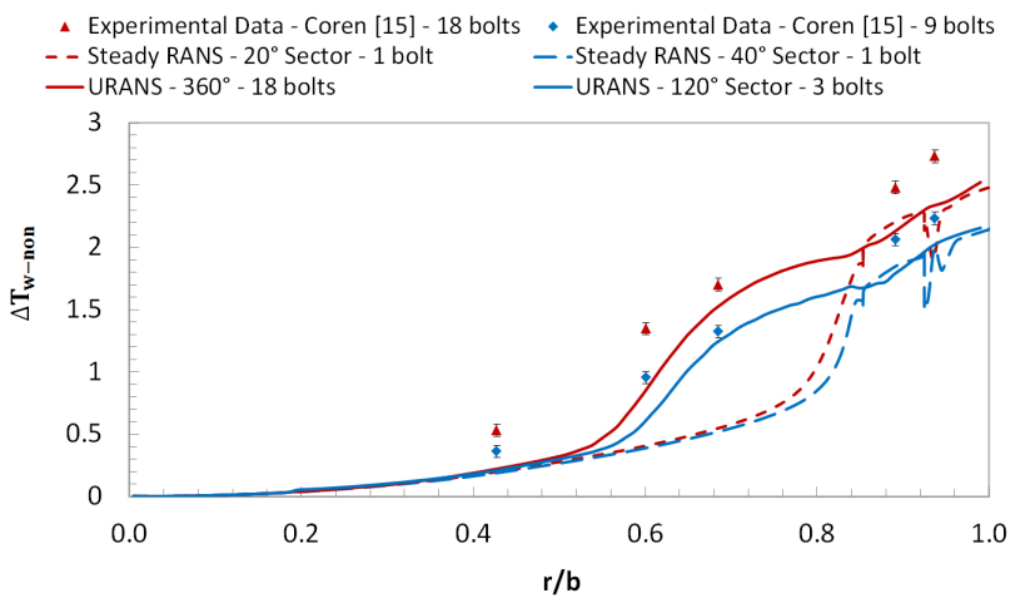

Figure 3. Comparison of non-dimensional adiabatic rotor wall to inlet air temperature difference for 18 and 9 bolts cases from steady CFD, circumferential average data from URANS calculations and experimental data from Coren [15]

(a)

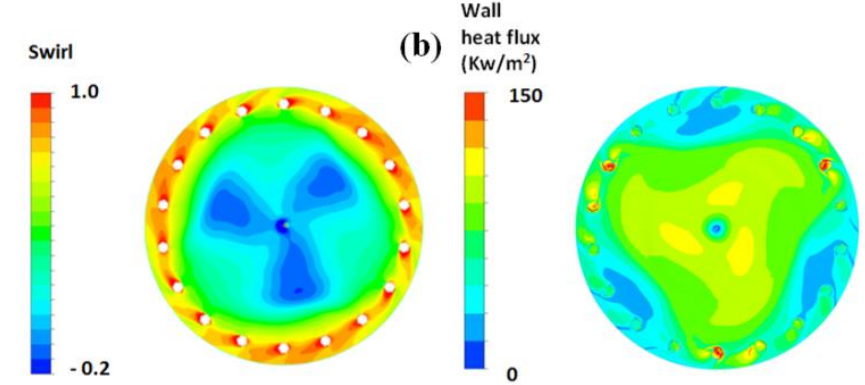

(c)

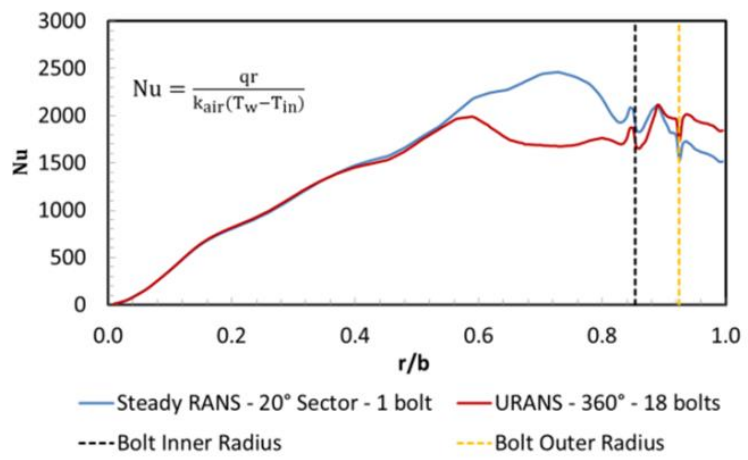

Figure 4. Contours of (a) instantaneous non-dimensional swirl at $x / s=0.25$ from the disc surface, (b) instantaneous wall heat flux after 40 disc rotations from unsteady CFD and (c) circumferentially averaged local Nusselt number from steady and unsteady CFD models 


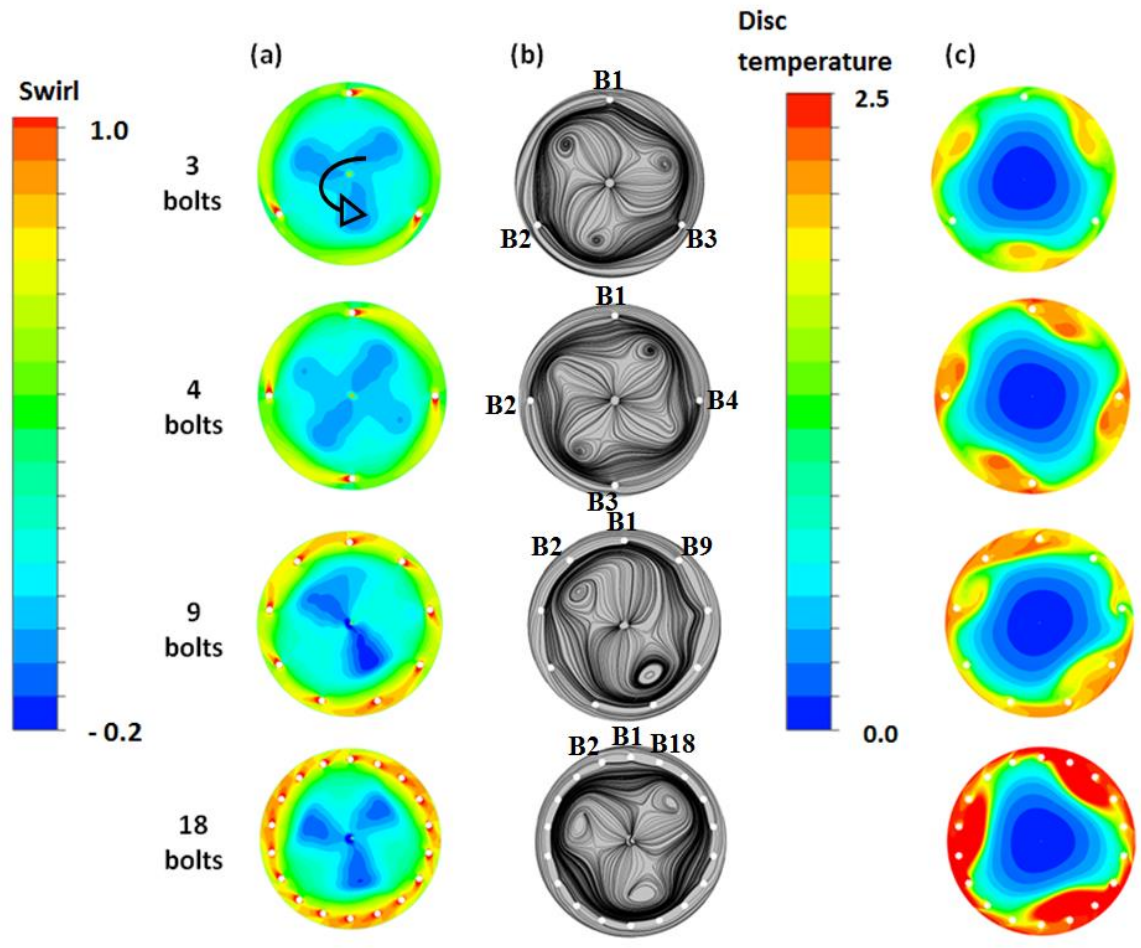

Figure 5. Contours of instantaneous (a) non-dimensional swirl, (b) surface streamlines at $x / s=0.25$ from the disc surface and (c) non-dimensional wall temperature after 40 disc revolutions for various bolt numbers

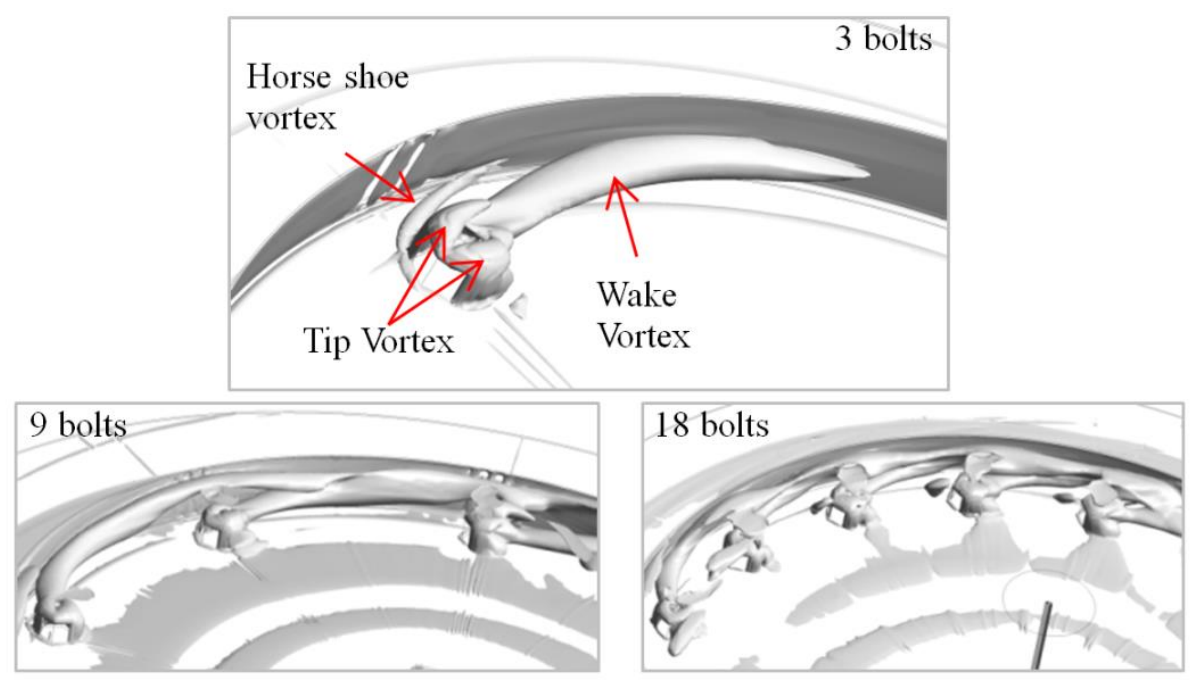

Figure 6. Iso-surface of Q-criterion for 3,9 and 18 bolts cases 
ASME J Gas Turb Pwr
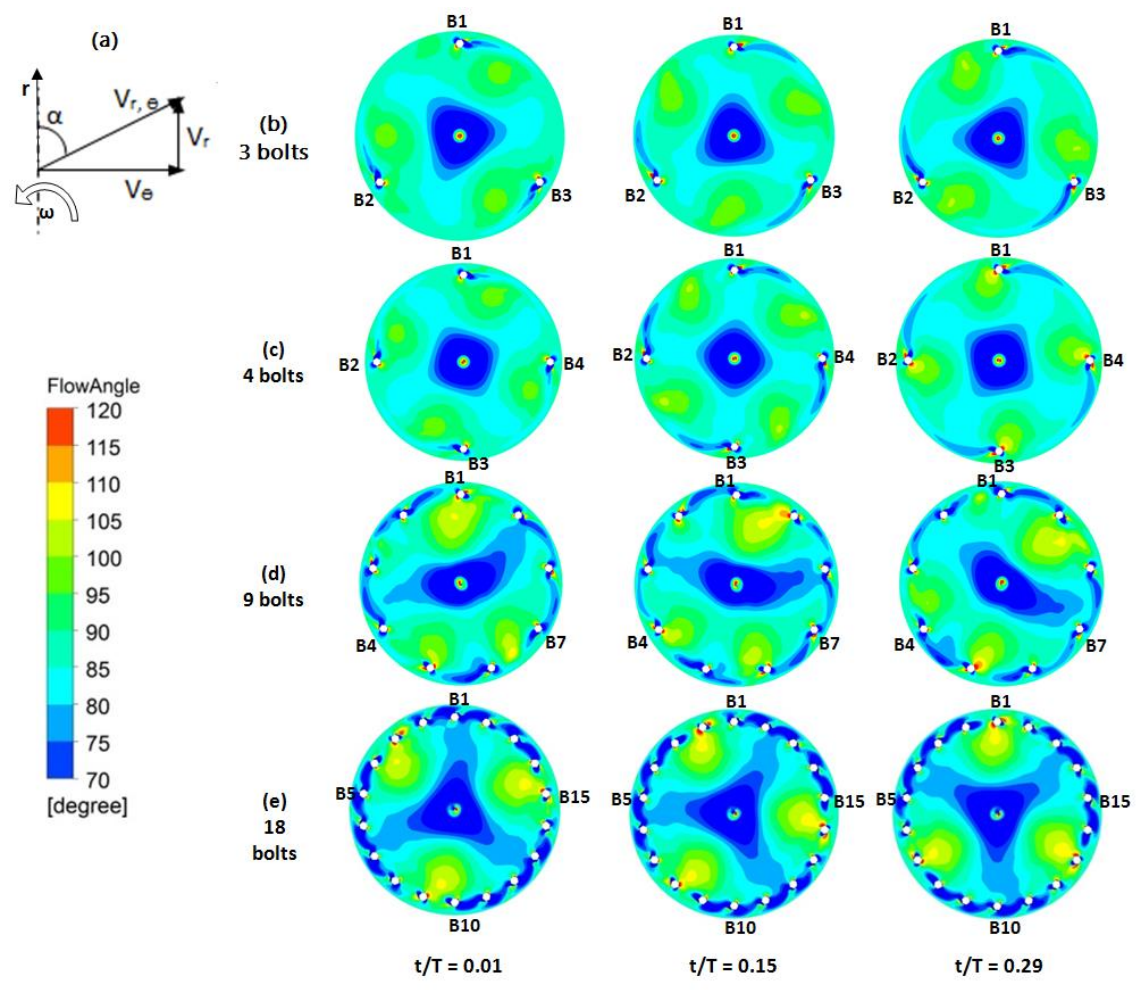

Figure 7. Contour plot of flow angle at various times after 40 disc rotations - for various bolt numbers

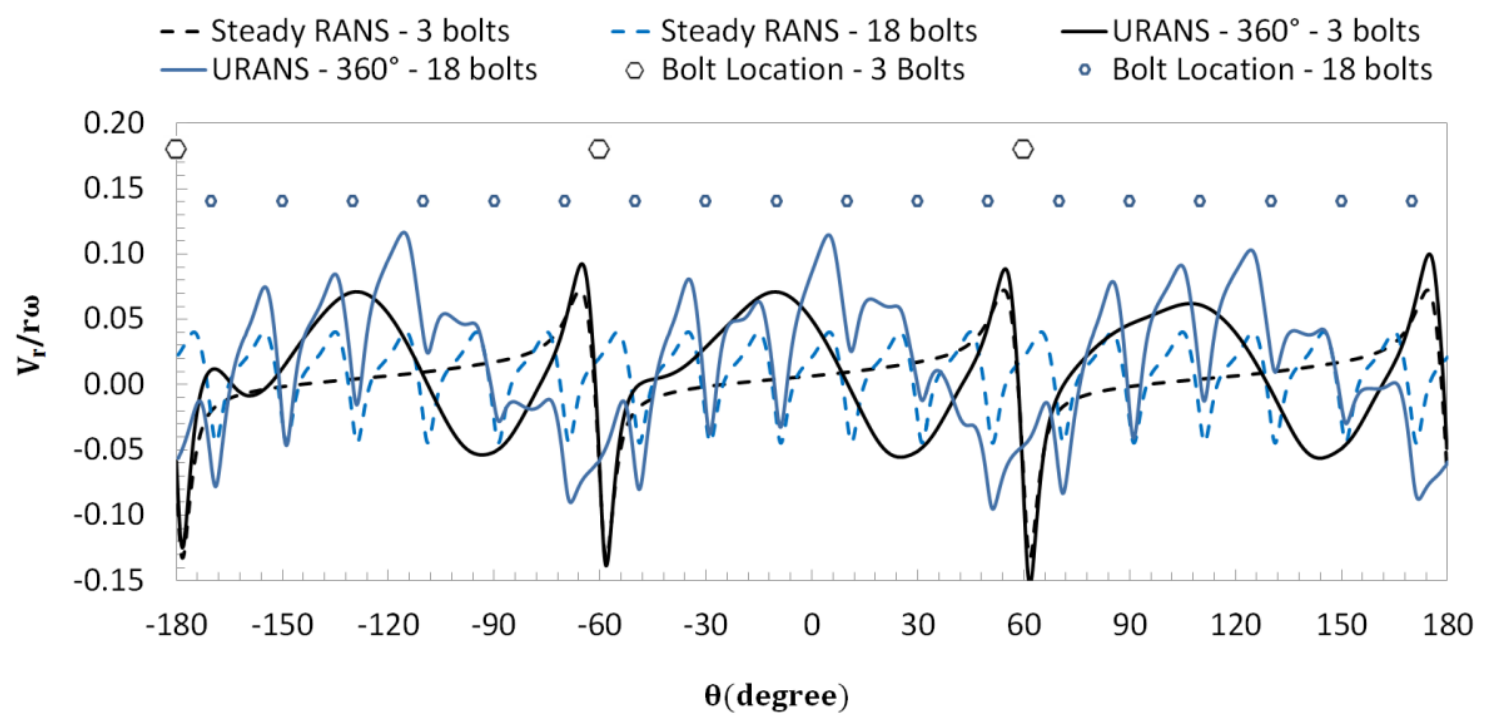

Figure 8. Circumferential variation of non-dimensional radial velocity inboard of the bolts $(r / b=0.82, x / s=0.4$ from disc surface) after 40 disc rotations 


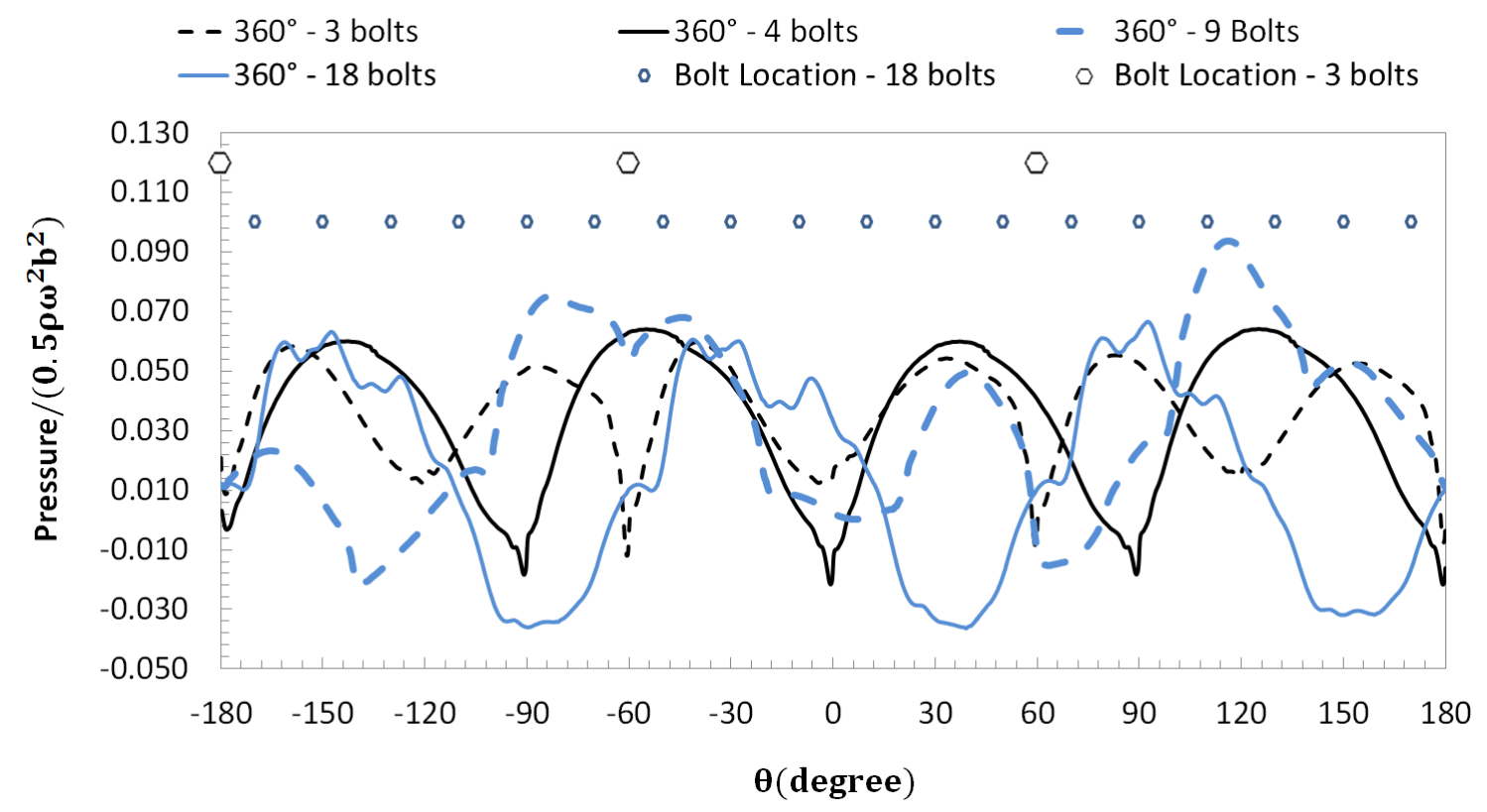

Figure 9. Instantaneous circumferential variation of static pressure on the casing surface $-x / s=0.25$ from the disc surface after 40 disc revolutions for various bolt numbers

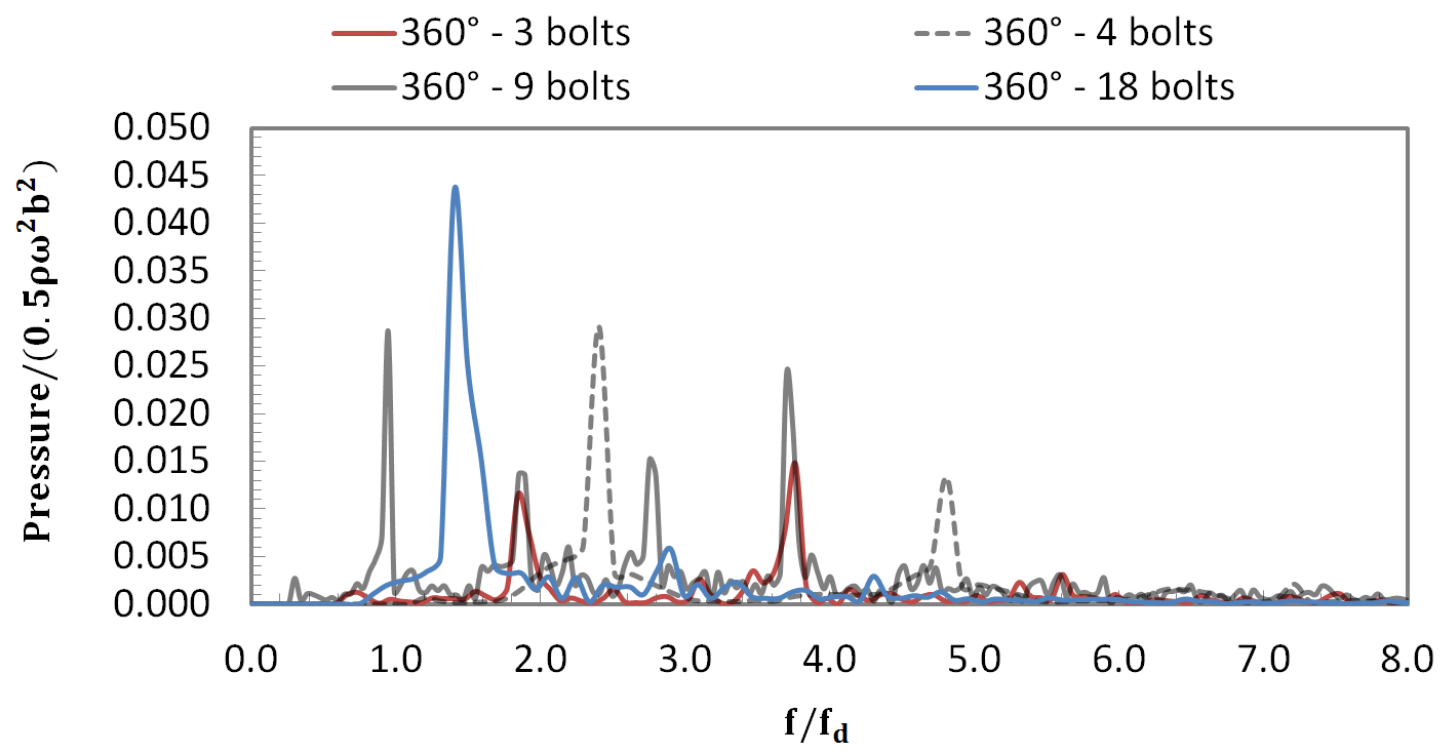

Figure 10. Discrete Fourier Transform of the pressure inboard of bolt $B 1$ at $r / b=0.82$, $\mathrm{x} / \mathrm{s}=0.4$ from the disc surface (in the rotating frame) for various bolt numbers 

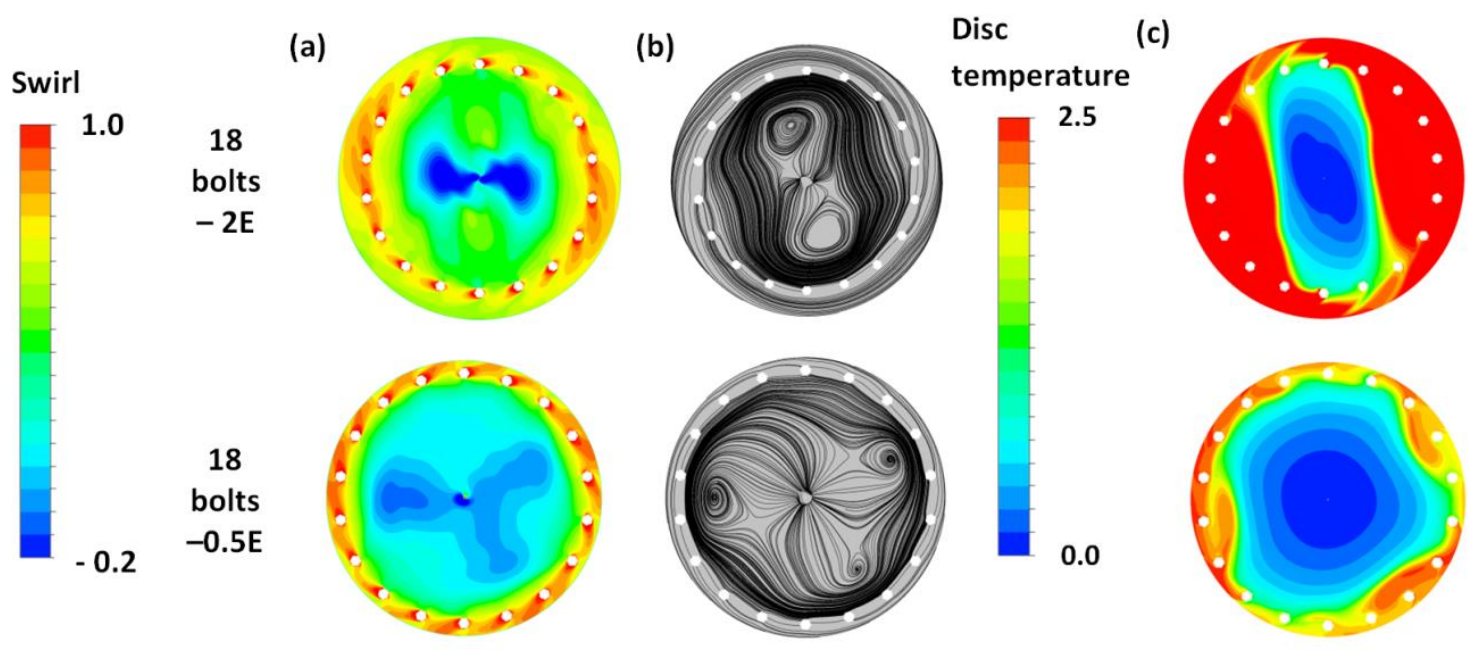

Figure 11. Contours of instantaneous (a) non-dimensional swirl (b) surface streamlines at $x / s=0.25$ and $(c)$ non-dimensional disc temperature after 40 disc revolutions for different bolts-to-shroud gap ratio 
(a) $-360^{\circ}-18$ bolts $\quad-360^{\circ}-18$ bolts $-2 \mathrm{E} \quad---360^{\circ}-18$ bolts $-0.5 \mathrm{E}$

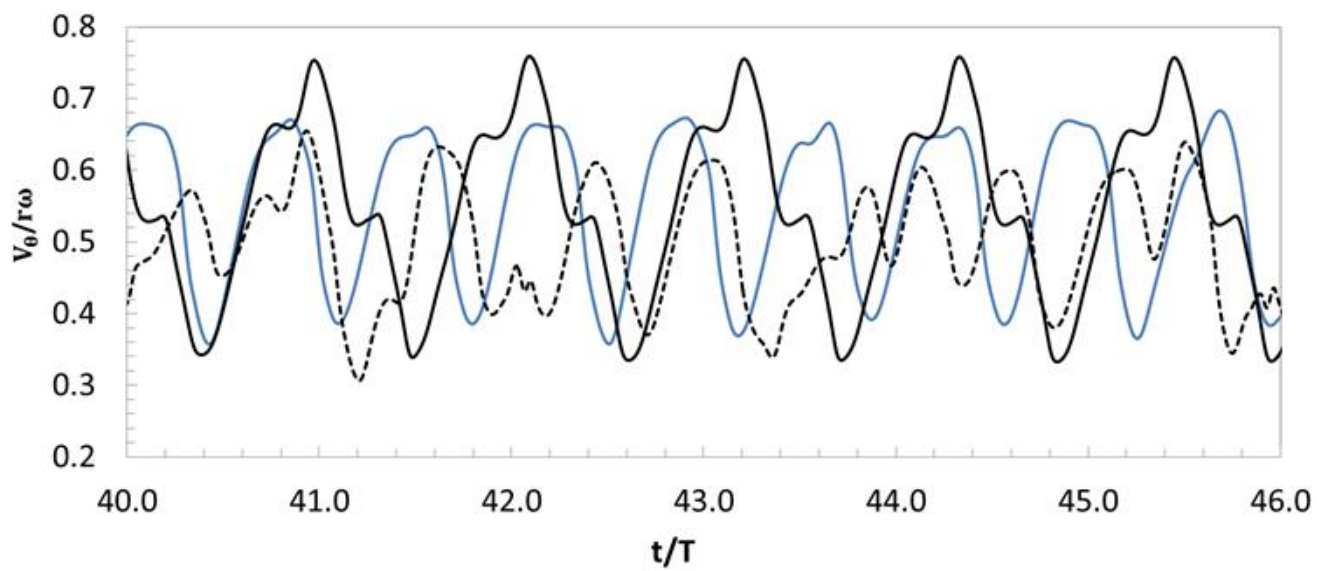

(b)

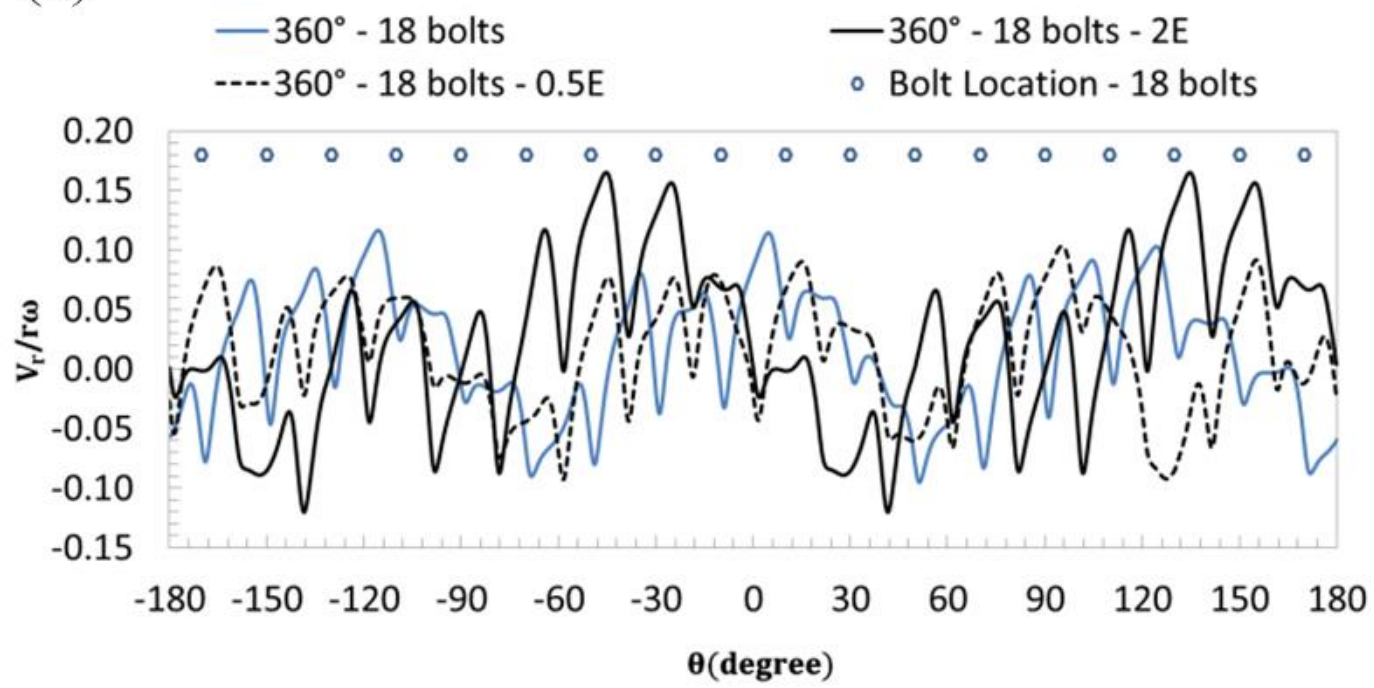

Figure 12. (a) Instantaneous non-dimensional swirl velocity inboard of bolt B1 and (b) circumferential variation of non-dimensional radial velocity inboard of the bolts $(r / b$ $=0.82, \mathrm{x} / \mathrm{s}=0.4$ from disc surface) for different bolt to shroud gap ratios 


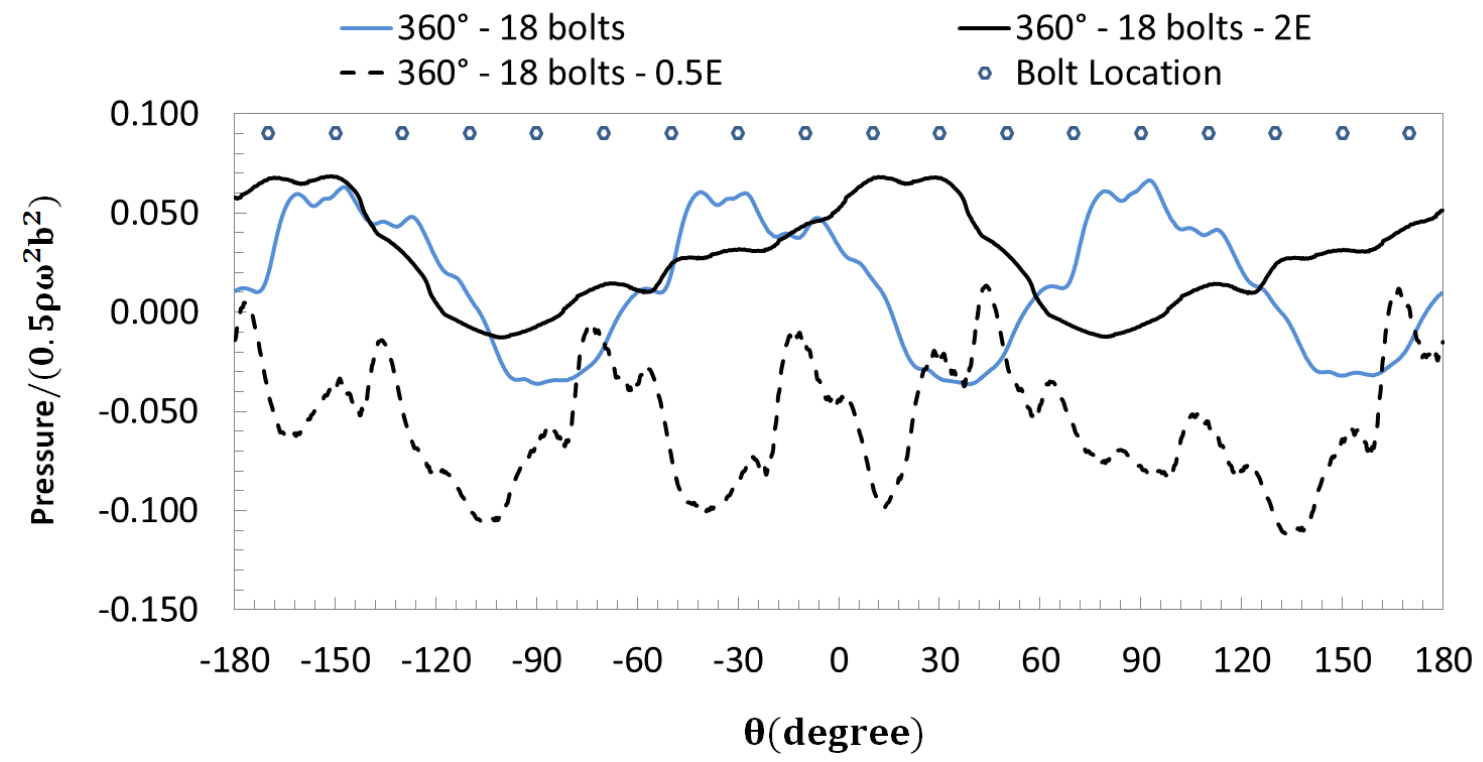

Figure 13. Instantaneous circumferential variation of static pressure on the casing surface $-\mathrm{x} / \mathrm{s}=0.25$ from the disc surface after 40 disc revolutions for different bolt to shroud gap ratios

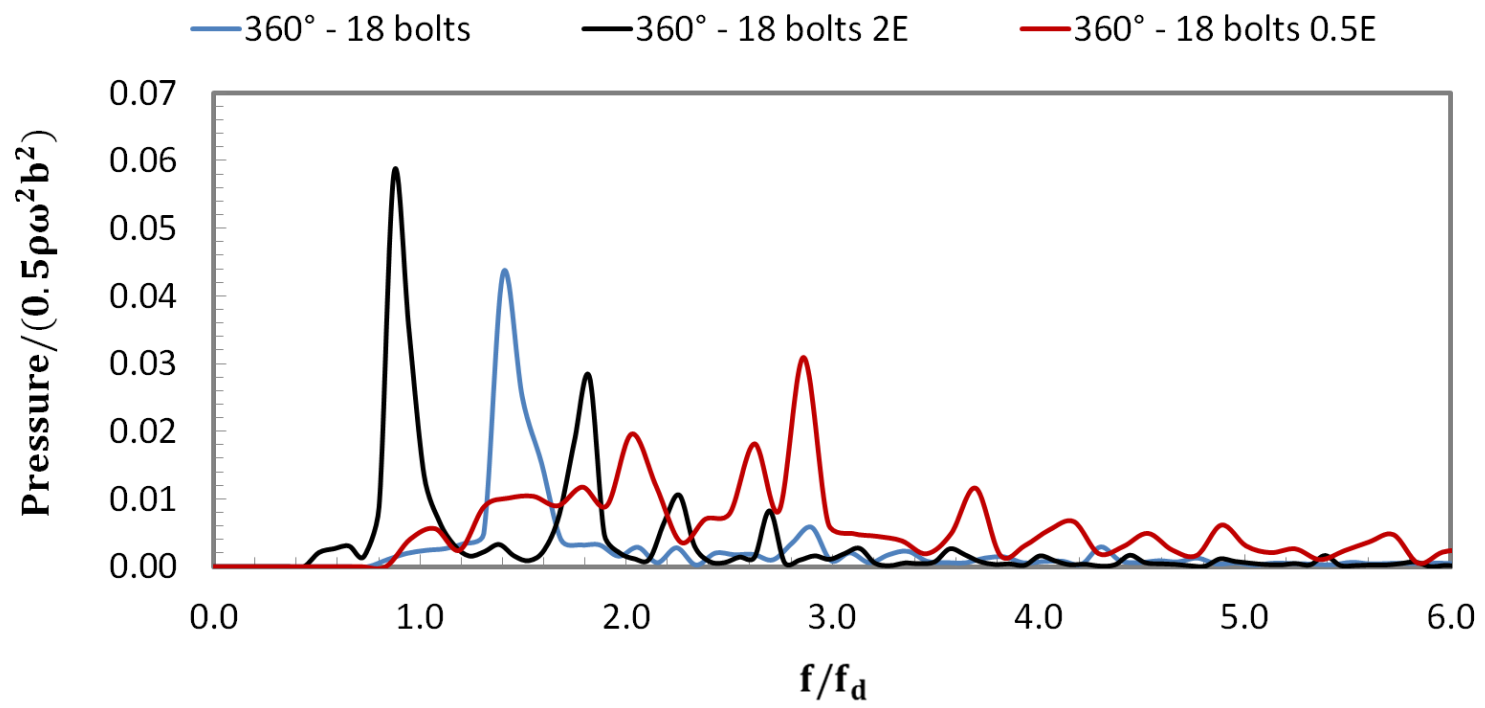

Figure 14. Discrete Fourier Transform of the pressure inboard of bolt $B 1$ at $r / b=0.82$, $x / s=0.4$ from the disc surface (in the rotating frame) for different bolts-to-shroud gap ratios 


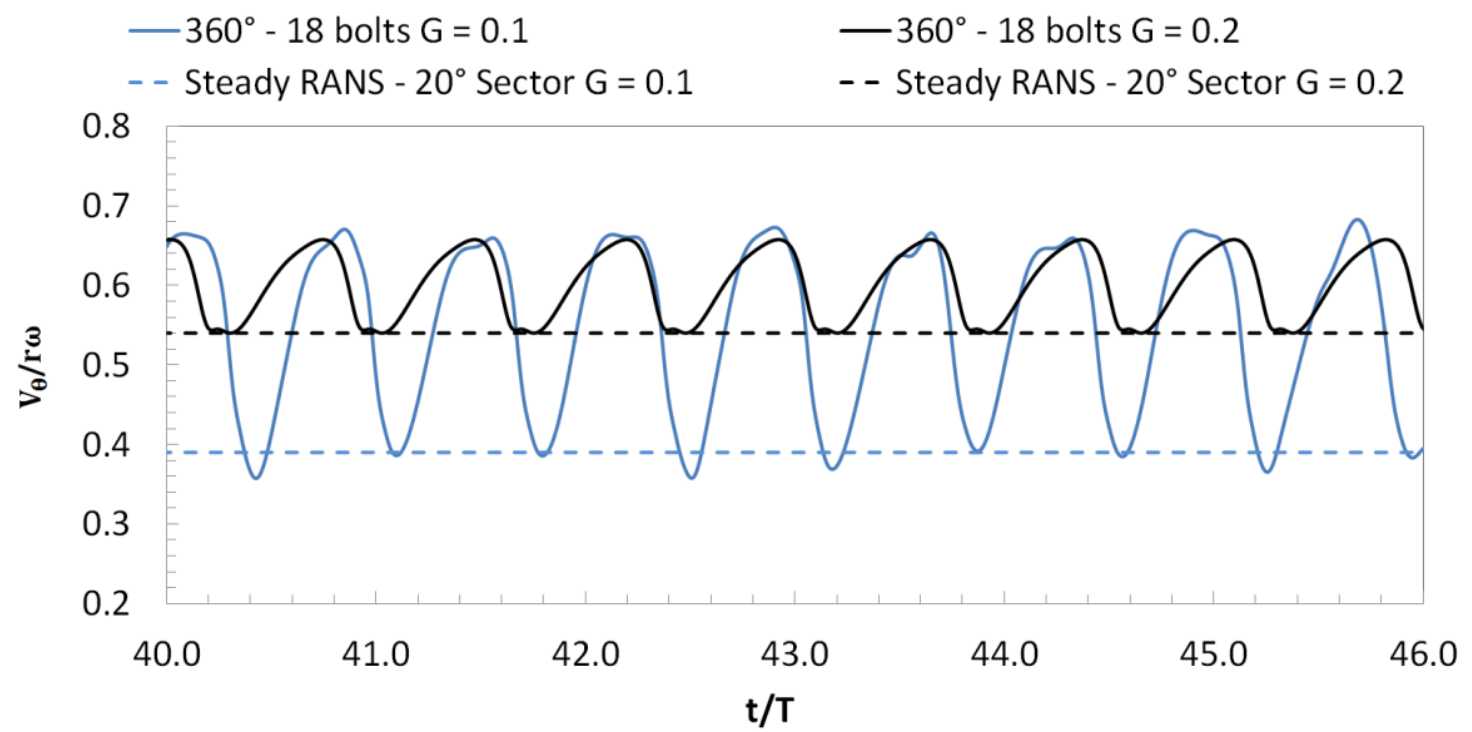

Figure 15. Instantaneous non-dimensional swirl velocity inboard of bolt B1 $(r / b=0.82$,

$\mathrm{x} / \mathrm{s}=0.4$ from disc surface) for design gap ratio and double the design gap ratio

\ Experimental Data - Coren [15] - 18Bolts - $\quad 360^{\circ}-18$ bolts $\mathrm{G}=0.1$

- $360^{\circ}-18$ bolts $\mathrm{G}=0.2 \quad-$ - Steady RANS - $20^{\circ}$ Sector $\mathrm{G}=0.1$

- - Steady RANS - $20^{\circ}$ Sector $\mathrm{G}=0.2$

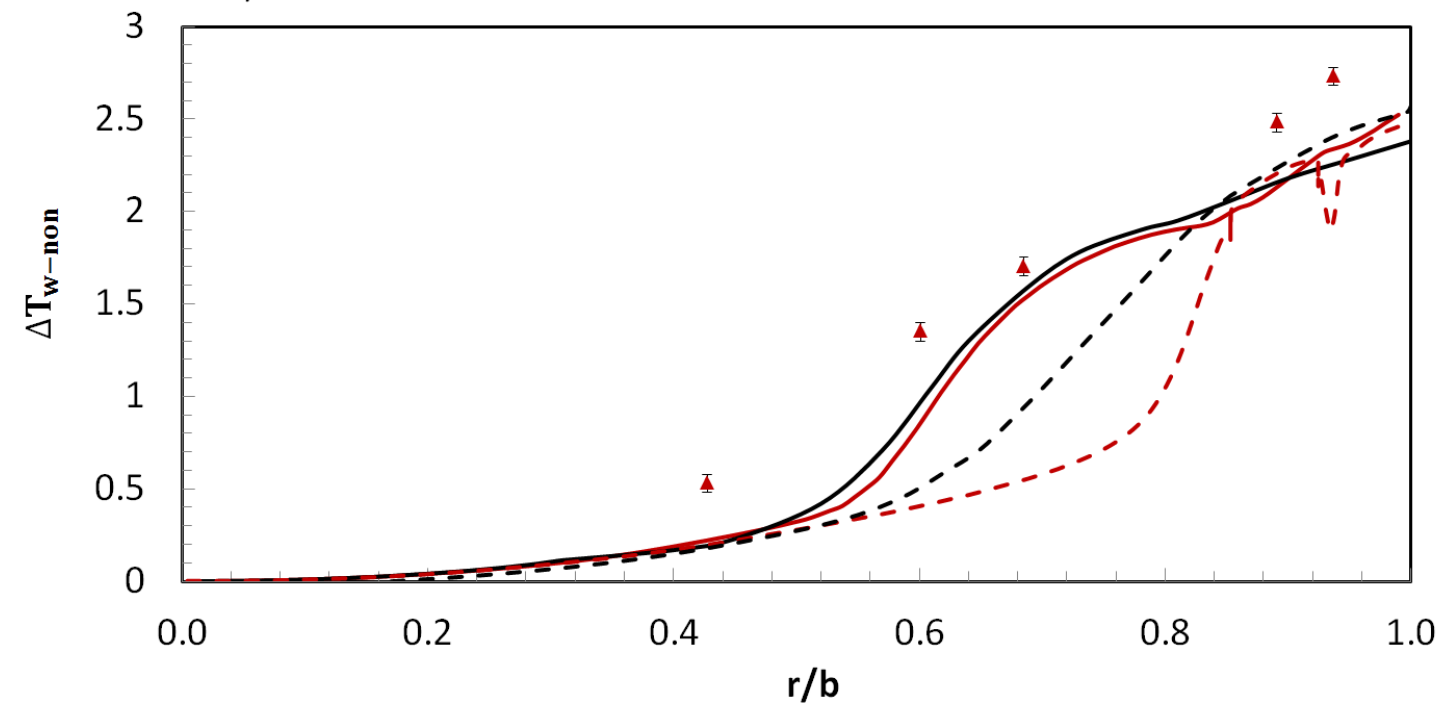

Figure 16. Influence of gap ratio on disc wall temperature profile - Comparison of steady and unsteady CFD models for design gap ratio and double the design gap ratio 


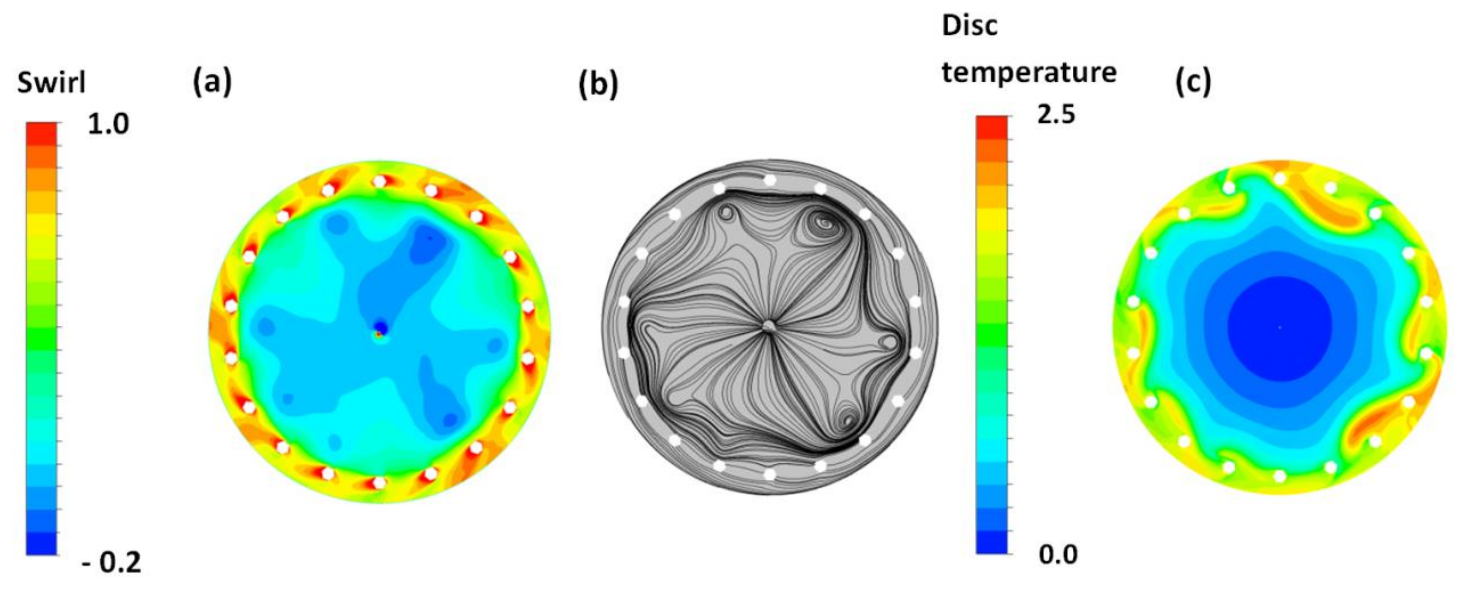

Figure 17. Contours of instantaneous (a) non-dimensional swirl (b) surface streamlines at $x / s=0.25$ from the disc surface and (c) non-dimensional disc temperature after 40 disc revolutions for high mass flow case

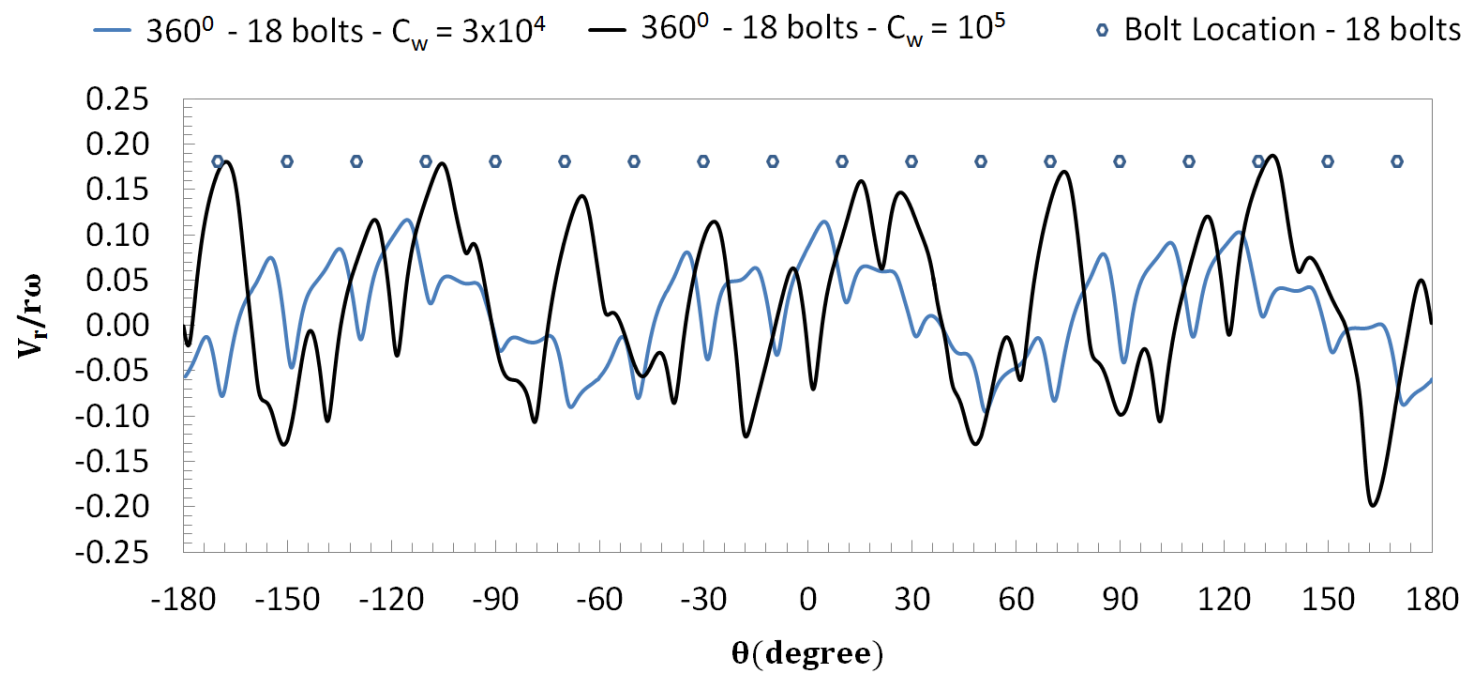

Figure 18. Instantaneous circumferential variation of non-dimensional radial velocity inboard of bolts $(r / b=0.82, x / s=0.4$ from disc surface) after 40 disc rotations 


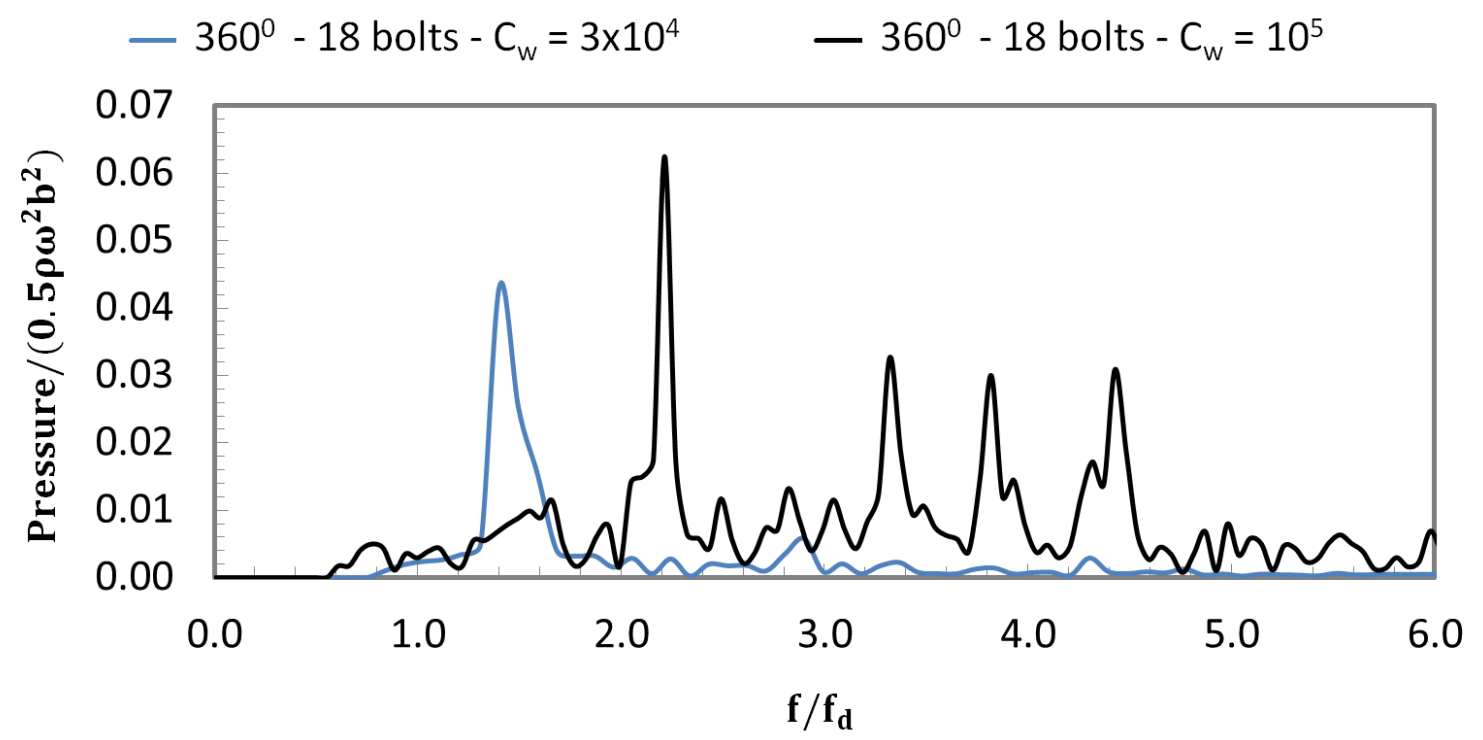

Figure 19. Discrete Fourier Transform of the pressure inboard of bolt $B 1$ at $r / b=0.82$, $\mathrm{x} / \mathrm{s}=0.4$ from the disc surface (in the rotating frame) from low and high throughflow cases 